\title{
AVALIAÇÃO DE PROCEDÊNCIAS DE Eucalyptus globulus ssp globulus SEGUNDO A QUALIDADE DE SUA MADEIRA PARA A PRODUÇÃO DE CELULOSE
}

\author{
JOSÉ FERNANDO RESQUIN PEREZ \\ Engenheiro Agrônomo
}

Orientador: Prof. Dr. LUIS ERNESTO BARRICHELO

Dissertação apresentada à Escola Superior de Agricultura "Luiz de Queiroz", Universidade de São Paulo, para obtenção do título de Mestre em Recursos Florestais, opção em Tecnologia de Produtos Florestais.

PIRACICABA

Estado de São Paulo - Brasil

Fevereiro - 2002 


\section{Errata}

\section{JOSÉ FERNANDO RESQUIN PEREZ. Avaliação de Procedências de Eucalyptus globulus ssp globulus Segundo a Qualidade de sua Madeira para a Produção de Celulose}
p. ítem linha
onde se lê
leia-se
$7 \quad 2.1 .1 \quad$ segunda
...competência
...concorrência
$17 \quad 2.3 .2 \quad$ Primeira
As células mais importantes das folhosas

\section{3.2.1 Décima}
...a maioria dos origens procedem da ilha de Tasmânia, salvo três

\section{$37 \quad 3.2 .2 \quad$ Décimo primeira \\ $\begin{array}{lll}42 & 3.2 .7 & \text { Décimo } \\ \text { Quinta }\end{array}$}
pu - peso úmido
...foi Ismeans. Para as...
434.1 . Décimo oitava
...as melhores procedências, são
$43 \quad 4.1 \quad$ Vigésima
...da região nordeste
$454.1 \quad$ Novena
...para a variável espessura da parede
$494.1 \quad$ Vigésima sétima
...fração parede acima de $60 \%$

$\begin{array}{lll}52 & 4.3 & \\ 63 & 4.5 & \text { Terceira } \\ 65 & 5 & \text { Sexta }\end{array}$
$r^{2}$ ...relacionados positivamente com o índice de enfeltramento ...da região nordeste
As células das madeiras das folhosas
...a maioria das procedências provem da ilha da Tasmânia, salvo uma
pu - peso úmido da amostra saturada em água
...foi Ismeans. Foram calculados coeficientes de correlação entre as características analisadas. Para as...
...as procedências com os valores mais altos, são
...da região nordeste da Tasmânia
...para a variável diâmetro do lume
coeficiente de flexibilidade acima de $60 \%$
$r$
..relacionados positivamente com o coeficiente de flexibilidade ...da região nordeste da Tasmânia

Eliminar parágrafos:

p. Ítem onde se lê

21 Determinar o possível...

32 Comprovando-se a...

33 Verificar a ...

444.1 Esta semelhança...

655 De modo geral...

675 Tanto para as... 
p. Ítem

37 3.2.2 A fórmula deverá ser a seguinte:

$$
D_{e}=\frac{\left(D_{1}^{2}+D_{2}^{2}\right)\left(D e_{1}+D e_{2}\right)+\left(D_{2}^{2}+D_{3}^{2}\right)\left(D e_{2}+D e_{2}\right)+\left(D_{3}^{2}+D_{4}^{2}\right)\left(D e_{2}+D e_{4}\right)+\left(D_{4}^{2}+D_{5}^{2}\right)\left(D e_{4}+D e_{5}\right)}{2\left(\left(D_{1}^{2}+D_{5}^{2}\right)+2\left(D_{2}^{2}+D_{3}^{2}+D_{4}^{2}\right)\right)}
$$




\section{Dados Internacionais de Catalogação na Publicação (CIP) DIVISÃO DE BIBLIOTECA E DOCUMENTAÇÃO - ESALQ/USP}

\section{Perez, José Fernando Resquin}

Avaliaçāo de procedências de Eucalyptus globulus ssp globulus segundo a qualidade de sua madeira para a produção de celulose / Fernando Resquin. - Piracicaba, 2002.

93 p. : il.

Dissertação (mestrado) - Escola Superior de Agricultura Luiz de Queiroz, 2002. Bibliografia.

1. Celulose de madeira 2. Eucalipto 3. Madeira - qualidade 4. Polpa de madeira I. Título

CDD 634.9734 


\section{AGRADECIMENTOS}

Ao Instituto Nacional de Investigación Agropecuária (INIA-Uruguay) por ter concedido a bolsa que permitiu-me a realização do Mestrado

Ao professor Barrichelo pela orientação no me trabalho

Aos professores Francidez Gomes, Cláudio Sansígolo e João Batista pela colaboração e valiosas sugestões na condução do experimento

A Gustavo Balmelli pelo aporte durante a elaboração do projeto e análise dos dados

A Zohra Bennadji pelo apoio no decorrer da minha capacitação

Aos funcionários Udemilson Ceribelli, Serigio Menochelli, Regina Busch, Francismara Duarte, Camila Sarto, Klebson e Gabriela Sabbadine pela colaboração durante as análises de laboratório

A meus companheiros Renato, Ana Maria, Antônio e Anne pela presença durante tudo este tempo

A Viviane, pelos momentos vividos 
...Hoy vas a entrar en mi pasado, en el pasado de mi vida. Tres cosas lleva el alma herida: amor, pesar, dolor. Hoy vas a entrar en mi pasado, hoy nuevas sendas tomaremos... 


\section{SUMÁRIO}

Página

LISTA DE FIGURAS........................................................................... vii

LISTA DE TABELAS............................................................................ ix

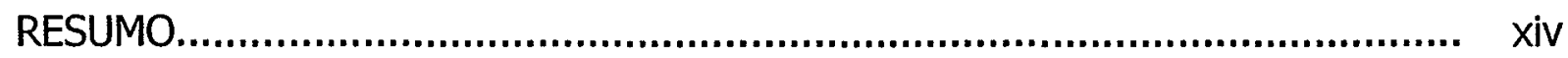

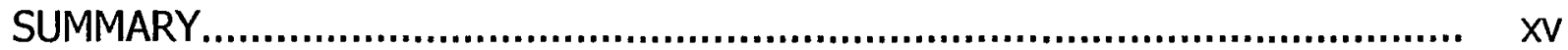

1 INTRODUÇÃO.............................................................................. 1

2 REVISÃO DE LITERATURA................................................................... 4

2.1 Principais características de Eucalyptus globulus..................................... 4

2.1.1 Variação na qualidade da polpa de E.globulus em função

da procedência...................................................... 6

2.2 Características gerais das espécies de Eucalyptus quanto a produção

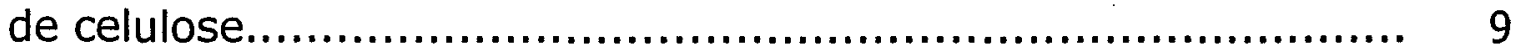

2.3 Parâmetros da madeira de Eucalyptus relacionados à polpação................. 11

2.3.1 Densidade básica.......................................................................... 11

2.3.2 Dimensões das fibras....................................................................... 16

2.3.3 Principais características físicas das polpas de Eucalyptus...................... 22

2.3.4 Composição química............................................................................ 27

2.3.4.1 Celulose.................................................................................... 28

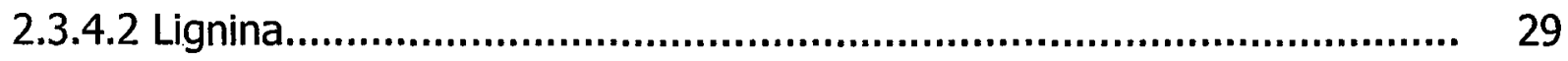

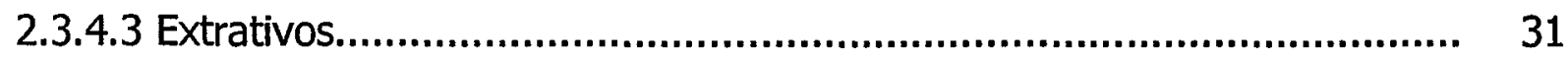

3 MATERIAL E MÉTODOS................................................................ 32 


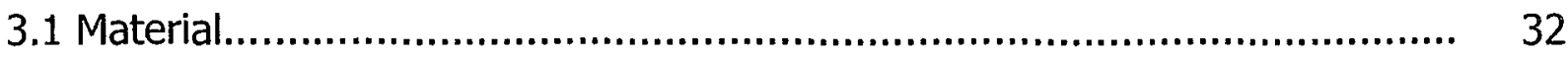

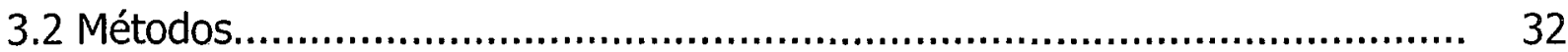

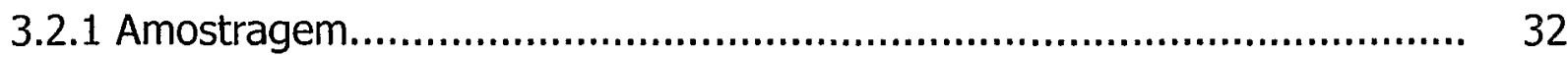

3.2.2. Densidade da madeira.................................................................. 36

3.2.3 Dimensões das fibras................................................................... 37

3.2.4. Composição química da madeira....................................................... 38

3.2.5. Produção de polpa....................................................................... 38

3.2.6 Ensaios das polpas..................................................................... 40

3.2.7 Análise estatística........................................................................ 41

4 RESULTADOS E DISCUSÃO .......................................................... 43

4.1 Densidade básica........................................................................... 43

4.2 Dimensões das fibras.................................................................. 45

4.3 Composição química.................................................................. 51

4.4 Cozimento kraft............................................................................ 54

4.5 Propriedades físicas e mecânicas das polpas......................................... 57

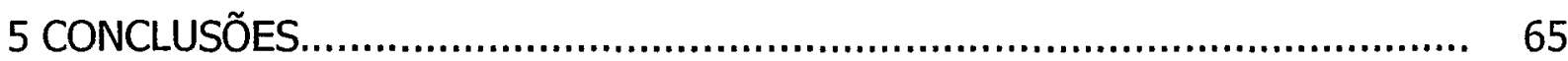

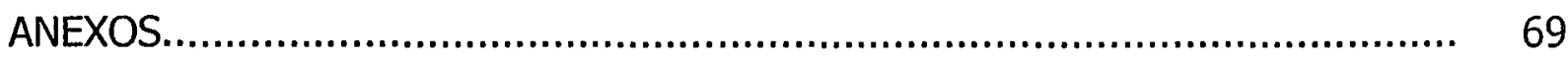

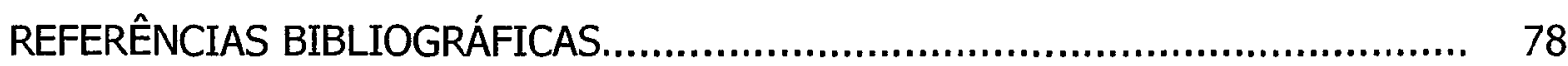




\section{LISTA DE FIGURAS}

Página

1 Área de ocorrência natural do E.globulus na Austrália............................ 5

2 Valores de densidade básica de E.globulus na área de distribuição natural...........................................................................

3 Valores de rendimento em polpa de E.globulus na área de distribuição natural.

4 Rendimento em celulose de várias espécies de Eucalyptus...................... 23

5 Índice de tração de várias espécies de Eucalyptus para 30 e $45{ }^{\circ}$ SR.......... 24

6 Índice de rasgo de várias espécies de Eucalyptus para 30 e $45^{\circ}$ SR.......... $\quad 25$

7 Índice de estouro de várias espécies de Eucalyptus para 30 e $45^{\circ}$ SR........ $\quad 26$

8 Densidade básica média das procedências de E.globulus........................ 45

9 Dimensões de fibras das procedências de $E$. globulus............................. 47

10 Índice de enfeltramento e fração parede das procedências de E.globulus.................................................................................. 50

11 Índice de runkel e coeficiente de flexibilidade das procedências de 51 E.globulus.

12 Composição química da madeira das procedências de E.globulus............. 53

13 Resultados do cozimento Kraft das procedências de E.globulus............. 56

14 Resultados de peso específico aparente, volume específico aparente, grau Shopper-Riegler, índice de tração de polpas das procedências 58 de $E$. globulus. 
15 Resultados do índice de arrebentamento, rasgo, energia absorvida na tração e rigidez na tração de polpas das procedências de E.globulus...... 


\section{LISTA DE TABELAS}

Página

1 Composição química quantitativa média da madeira de Eucalyptus............ 27

2 Composição química quantitativa das madeiras de várias espécies de Eucalyptus................................................................................ 28

3 Lista de materiais genéticos instalados no ensaio de procedências/progênies no Uruguai

4 Valores de densidade básica em $\mathrm{g} / \mathrm{cm}^{3}$ das progênies que compõem cada uma das procedências/progênies de E. globulus.

5 Comprimento, largura, diâmetro do lume e espessura da parede das fibras das procedências de $E$. globulus

6 Índices calculados a partir dos valores das dimensões das fibras das procedências de E.globuluis

7 Teores de lignina total, holocelulose e extrativos totais das procedências de E.globulus.

8 Valores de rendimento depurado, número kappa, teor de rejeitos e relação rendimento/kappa das procedências de E.globulus.

9 Valores de correlação da densidade básica com parâmetros da deslignificação e composição química...................................................

10 Valores de comprimento das fibras $(\mathrm{mm})$ das progênies que compõem cada uma das procedências de E.globulus. 
11 Valores de largura das fibras $(\mu \mathrm{m})$ das progênies que compõem cada uma das procedências de E.globulus.............................................. $\quad 70$

12 Valores de diâmetro do lume das fibras $(\mu \mathrm{m})$ das progênies que compõem cada uma das procedências de E.globulus ......................... 71

13 Valores de espessura da parede das fibras $(\mu \mathrm{m})$ das progênies que compõem cada uma das procedências de E.globulus.......................... 71

14 Teores de lignina total (\%) das progênies que compõem cada uma das procedências de E.globulus...................................................... $\quad 72$

15 Teores de holocelulose (\%) das progênies que compõem cada uma das procedências de E.globulus...................................................... 72

16 Teores de extrativos totais (\%) das progênies que compõem cada uma das procedências de E.globulus............................................... 73

17 Valores de rendimento depurado (\%) das progênies que compõem cada uma das procedências de E.globulus..........................................

18 Valores de número kappa das progênies que compõem cada uma das procedências de E.globulus.............................................................

19 Teores de rejeito base madeira (\%) das progênies que compõem cada uma das procedências de E.globulus..........................................

20 Valores da relação rendimento depurado/kappa das progênies que compõem cada uma das procedências de E.globulus.............................

21 Valores de peso específico aparente $\left(\mathrm{g} / \mathrm{cm}^{3}\right)$ das procedências de E.globlus em função de três níveis de refino (revoluções)....................... 75

22 Valores do grau Shopper-Riegler ( ${ }^{\circ} \mathrm{SR}$ ) das procedências de E.globulus em função de três níveis de refino (revoluções)................... 75

23 Valores de volume específico aparente $\left(\mathrm{cm}^{3} / \mathrm{g}\right)$ das procedências de E.globulus em função de três níveis de refino (revoluções).................... 76

24 Valores do índice de tração $(\mathrm{N} . \mathrm{m} / \mathrm{g})$ das procedências de E.globulus em função de três níveis de refino (revoluções).................. 76 
25 Valores do índice de rasgo $\left(\mathrm{mN} . \mathrm{m}^{2} / \mathrm{g}\right)$ das procedências de E.globulus em função de três niveis de refino (revoluções)

26 Valores do índice de arrebentamento $\left(\mathrm{kPa} \cdot \mathrm{m}^{2} / \mathrm{g}\right)$ das procedências de E.globulus em função de três níveis de refino (revoluções).

27 Valores do índice de energia absorvida na tração $(\mathrm{J} / \mathrm{g})$ das procedências de E.globulus em função de três níveis de refino (revoluções)...

28 Valores do índice de rigidez na tração $(\mathrm{N} . \mathrm{m} / \mathrm{g})$ das procedências de E.globulus em função de três níveis de refino (revoluções). 


\title{
AVALIAÇÃo DE PROCEDÊNCIAS DE Eucalyptus globulus ssp globulus SEGUNDO A QUALIDADE DE SUA MADEIRA PARA A PRODUÇÃO DE CELULOSE
}

\author{
Autor: FERNANDO RESQUIN \\ Orientador: Prof. LUIZ ERNESTO BARRICHELO
}

\section{RESUMO}

O trabalho procurou avaliar um ensaio de procedências de Eucalyptus globulus implantado no Uruguai em 1995, do ponto de vista da qualidade da madeira. Amostras de madeira provenientes de sete procedências da Tasmânia e sul de Vitória foram analisadas para densidade básica, dimensões de fibras, composição química da madeira e polpação Kraft incluindo rendimento depurado, número Kappa, refino e resistências da polpa. As procedências que mostraram os melhores valores em termos de rendimento depurado, número Kappa e rejeitos foram a 1 (sul de Vitória), 10 (ilha Capa Barren, do estreito de Bass) e 12 (nordeste da Tasmânia). As procedências 10 e 12 foram as que mostraram a melhor performance em termos de facilidade de refino e resistências da polpa. As relações entre propriedades da madeira e polpação Kraft foram discutidas para escolher as melhores procedências. 


\title{
PULP AND WOOD QUALITY FROM Eucalyptus globulus ssp globulus PROVENANCES
}

\author{
Author: FERNANDO RESQUIN \\ Adviser: Prof. LUIZ ERNESTO BARRICHELO
}

\section{SUMMARY}

The work look for analyze provenances trials of Eucalyptus globulus established in Uruguay in 1995 to evaluate the growth and wood quality. Samples of wood from trees in seven provenances of Tasmanian and southern Victorian were analysed for basic density, fiber dimensions, wood chemicals components and Kraft pulping including yield, Kappa number, beating and pulp strengths. The provenances that showed the best values in term of screened yield, Kappa number and rejects were: 1 (south of Victoria), 10 (Bass estreit)

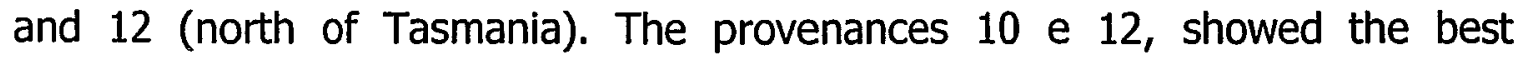
performance in term of beating easy and pulp strengths. Relations between wood properties and Kraft pulping were discussed for to choose the best provenances 


\section{INTRODUÇÃO}

Dentre a amplitude de gêneros, os Eucaliptos são os que tem recebido maior atenção nas últimas décadas por parte dos pesquisadores e industriais, devido ao grande número de espécies que compreende, a ampla gama de possibilidades de adaptação ecológica e climática, aos bons crescimentos e resultados obtidos na indústria de celulose e papel (Bustamente \& Santos, 1981)

Embora as espécies deste gênero superam as 600 , o número das que podem ter interesse em cada país é muito mais reduzido, levando em consideração seu possivel aproveitamento como matéria-prima celulósica.

Os resultados das pesquisas nesta área têm demonstrado que várias das espécies possuem madeiras de boas características para a produção de celulose e papel. Isto tem permitido afirmar que atualmente o número de espécies que interessa avaliar, não passa das 30. Deste grupo, as espécies que mais tem sido estudadas são E.grandis, E.saligna, E.urophylLa, E.globulus, E. camaldulensis e E.viminalis, dentre outras. Destas, o E.globulus destaca-se como uma das espécies com boa aptidão para a produção de celulose.

Estes estudos também têm contribuído para saber que neste gênero existem uma ampla gama de fatores que determinam grandes diferenças quanto à qualidade da celulose. Entre estes fatores, a espécie, a procedência $\mathrm{e}$ 
a idade das árvores mencionam-se como as mais importantes.

Se observamos a situação dos países da região sul de América Latina (Uruguai e Argentina) vemos que o Eucalyptus globulus é uma das espécies mais plantadas para tais fins, com materiais provenientes fundamentalmente da Austrália (por ser o pais de origem desta espécie), se bem que também têm sido introduzidos materiais da Espanha, Chile e Portugal com sucesso.

Analisando-se as fontes de variação dentro desta espécie (procedência, lugar de implantação, etc.) avaliações têm sido feitas com o objetivo de identificar materiais que mostrem bom crescimento além da boa aptidão para a produção de celulose. No Uruguai, dentro do programa de melhoramento genético de Eucalyptus spp. do Instituto Nacional de Investigación Agropecuária (INIA), têm sido instalados, nos últimos anos, ensaios onde avaliam-se várias fontes de sementes da Austrália (origens ou procedências) e dentro destes diferentes lotes de sementes de árvores bem identificados (progênies ou famílias). Até agora as avaliações têm sido feitas do ponto de vista do crescimento, mas dada a idade dos mesmos, surge a necessidade de fazer uma avaliação tendo em conta a produção de celulose.

O presente estudo tem como objetivo avaliar a qualidade da madeira, em laboratório, de várias procedências de Eucalyptus globulus provenientes da Austrália, para a produção de celulose através do processo sulfato.

Os resultados obtidos vão permitir:

1) Determinar o possível padrão geográfico de variação das procedências, quanto à qualidade da madeira para produção de celulose. 
2) Comprovando-se a existência de uma variação entre procedências, selecionar-se aquelas melhores para a produção de sementes melhoradas.

3) Verificar a possibilidade de se correlacionar as características analisadas (por exemplo, rendimento em polpa e sus propriedades) com características facilmente mensuráveis nos ensaios e que não requeiram cortar a árvore (por exemplo, baguetas para determinar densidade), e com isso fazer-se uma seleção indireta. 


\section{REVISÃO DE LITERATURA}

\subsection{Principais características do Eucalyptus globulus}

O Eucalyptus globulus Labill. subsp. globulus é originário da ilha de Tasmânia, Promontório de Wilson e costas do estado de Victoria além das ilhas do estreito de Bass entre a Tasmânia e o continente Australiano (Figura 1). As latitudes correspondem de $38^{\circ} 30^{\prime}$ a $43^{\circ} 30^{\prime} \mathrm{S}$ e a altitude de 0 a $330 \mathrm{~m}$ (FAO, 1981).

O E.globulus tem sido usado em vários países e talvez, seja a espécie de Eucalyptus mais amplamente usada no mundo inteiro. Na Espanha, Portugal e Chile é das espécies de folhosas mais importantes. Contudo, é também usada comercialmente em alguns outros países incluindo Rhodesia, Congo, Kenya, Etiópia, Marrocos, Itália, Grécia, Índia, Equador, Colômbia, Bolívia, Peru, Argentina, Sudeste do Brasil e Uruguai (Orme, 1978).

A madeira desta espécie é muito utilizada como fonte de fibra curta na indústria do papel. Esta espécie combina o rápido crescimento, madeira de media a alta densidade básica, alto rendimento de polpa e boas propriedades da fibra e do papel (Pereira \& Sardinha, 1984; Borralho et al.,1992; Pereira, et al.,1995; Kibblewhite et al., 2000).

No Brasil, juntamente com E.robusta, foi, provavelmente um dois 
primeiros Eucalyptus a serem introduzidos (Gonzaga et al., 1984). Barrichelo \& Foelkel (1976) produziram celulose sulfato a partir de madeira desta espécie obtendo bons resultados quanto ao rendimento, resistência à tração, ao arrebentamento e alongamento, os quais foram similares aos obtidos com E.saligna e E.grandis. Similares resultados foram obtidos por vários autores, os quais mostram que a madeira de E.globulus é de fácil desliginificação, obtendo altos valores de resistência à tração e arrebentamento (Foelkel, 1974; Queiroz, 1972; Zárate \& Gironda, 1981; Barrichelo \& Brito, 1983; Cáceres, 1983; Gonzaga et al., 1984 a,b; Kibblewhite et al., 2000).

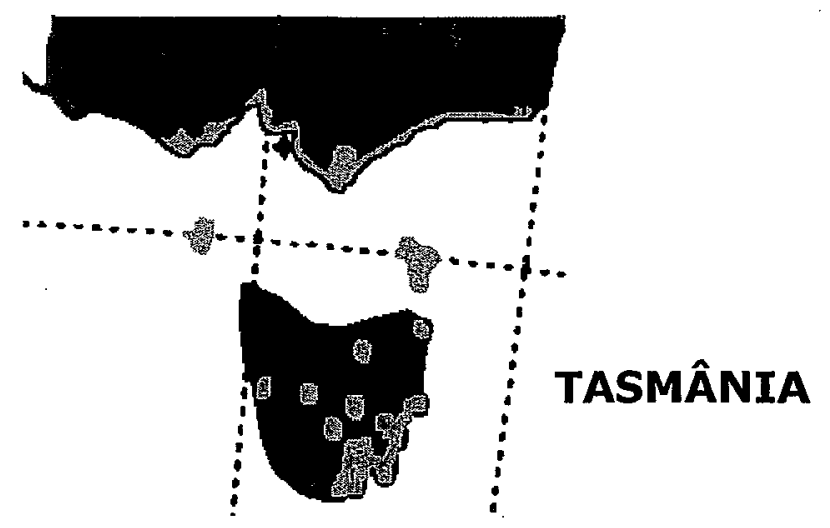

ÁREA DE DISTRIBUIÇÃo

NATURAL DE E.globulus

ssp globulus

Figura 1 - Área de ocorrência do E.globulus na Austrália 
A polpa desta espécie é fácil de branquear e é empregada na fabricação de papéis de imprimir e de escrever e papéis-base para pintar. No processo kraft produz como resultado maiores rendimentos me polpa e melhores características mecânicas do que no processo soda, porém as diferenças são relativamente pequenas. Destaca-se por seu baixo teor de lignina além de seu alto conteúdo de pentosanas totais. $O$ teor de lignina da uma idéia da dificuldade no cozimento e as pentosanas estão relacionadas com as propriedades do papel dependentes da interligação entre as fibras (Queiroz, 1972).

Quanto às características físicas e de seus elementos anatômicos o E.globulus é uma espécie de densidade básica com valores que variam de 0,430 a $0,710 \mathrm{~g} / \mathrm{cm}^{3}$, fibras tipo libriformes e fibrotraqueídeos relativamente curtas com um comprimento 0,67 a 1,22 mm, estreitas com uma largura entre 11,5 a $21.5 \mu \mathrm{m}$, uma espessura de parede variando entre 3,4 a $12 \mu \mathrm{m}$ e um diâmetro do lume com valores de 4 a $15 \mu \mathrm{m}$ (Queiroz, 1972; Foelkel, 1974; Barrichelo \& Foelkel, 1976; Palmers at al., 1982; Barrichelo \& Brito, 1983; Brito et al., 1983; Cáceres, 1983; Turner et al.,1983; Gonzaga, 1984a,b; Tomazello Filho, 1985; Gamoeda, 1988; Borralho et al., 1992; Valente et al., 1992; Ferrari \& Mughini, 1995; Tomé et al., 1995; Low \& Shelbourne, 1999; Schimleck et al., 1999; Kibblewhite et al., 2000).

\subsubsection{Variação na qualidade da polpa de E.globulus em função da procedência}

Esta espécie apresenta uma ampla distribuição geográfica, mas restringida a limitados tipos de ambientes como por um lado áreas de poucas 
precipitações, altitudes com baixas temperaturas e por outro regiões bem drenadas com altas precipitações e em competência com outras espécies. Todos estes fatores indicam a probabilidade de um alto grau de variação genética dentro da espécie (Turner et al., 1983; Dutkowski et al., 1997).

Vários estudos com esta espécie tem mostrado que existe uma substancial variação tanto nas taxas de crescimento quanto nas características de polpação entre e dentro de procedências. Por outro lado, tem sido determinadas que dentro da região de origem desta espécie (Austrália), as melhores procedências do ponto de vista da polpa corresponde a uma pequena área na costa oeste da Tasmânia (Orme, 1983). De acordo com este autor, apesar das diferenças existentes entre idades, manejo e aspectos ambientais, geralmente ocorre uma maior uniformidade nas propriedades da polpa dentro de procedências do que entre procedências. Estes resultados tem implicações extremamente importantes para as plantações industriais já que as melhores procedências em termos de qualidade da polpa procedem da costa oeste da Tasmânia em vez da costa leste e sudeste, as quais são a provável região de origem da maioria das plantações desta espécie no mundo inteiro (Orme, 1983).

Resultados obtidos por Turner et al. (1983), mostram que a qualidade da polpação a partir de amostras de madeira de E.globulus, varia amplamente dependendo da área de procedência (Figuras 2 e 3 ). Segundo eles, só uma pequena parte da variação nas propriedades da madeira pode ser explicada em termos da idade, fatores climáticos ou geográficos e portanto espera-se que pelo menos parte da variabilidade seja derivada e que posa ser usada na seleção e melhoramento das características da polpa. 


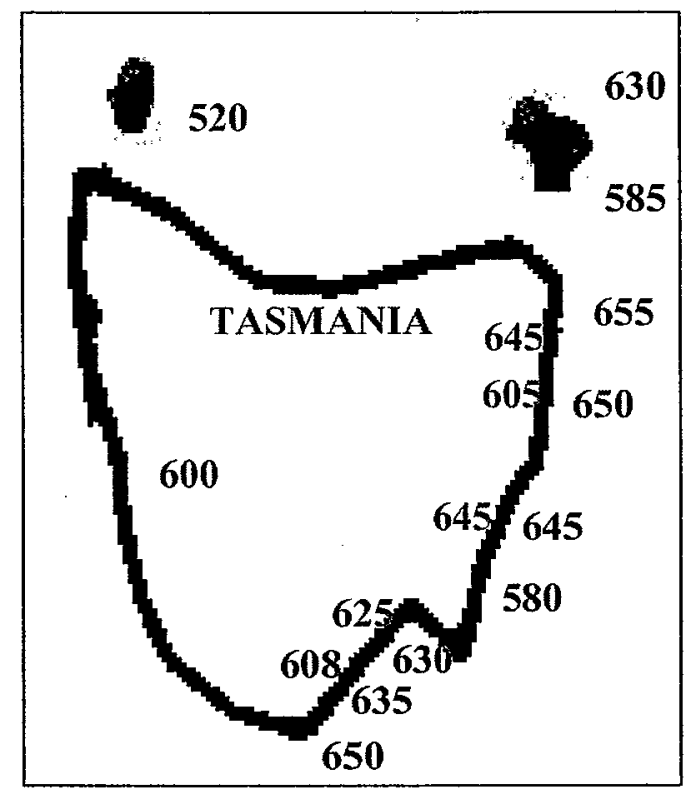

Figura 2 - Valores de densidade básica de E.globulus na área de distribuição natural. (Fonte: Turner et al., 1983)

Resultados similares também tem sido reportados por vários autores, mostrando a variação das características da madeira relacionadas à polpação em função da procedência (Ferrari \& Mughini, 1995; Pereira et al., 1995; Willimas et al., 1995). 


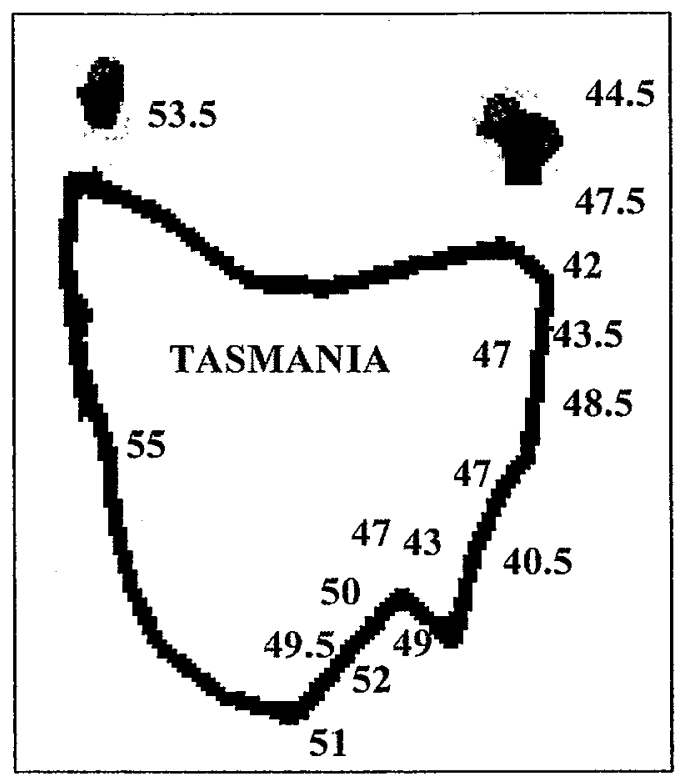

Figura 3 - Valores de rendimento em polpa de E.globulus na área de distribuição natural (Fonte: Turner et al.,1983)

Dutkowski et al. (1997), avaliando a variação genética de várias procedências da Austrália de E.globulus quanto à resistência ao déficit hídrico, DAP, penetração do pilodyn e espessura da casca concluíram que existem diferenças entre localidades e que estas podem serem agrupadas em raças geográficas. Esta divisão racial conduz à identificação de novas divisões dentro de raças e a uma melhor identificação das fronteiras das mesmas.

\subsection{Características gerais das espécies de Eucalyptus quanto a produção de celulose}

A bibliografia revisada em geral é coincidente em indicar as vantagens da produção de celulose para papel de fibra curta a partir de espécies do gênero Eucalyptus (Mello et al., 1977; Cáceres, 1983). Também é notória a diferença existente entre espécies do ponto de vista da aptidão de sua madeira 
para a produção de polpa para papel. Há que ter em conta que este gênero é composto por mais de 600 espécies que crescem nas condições mais diversas. Este fenômeno é mais notório ainda, no caso do cruzamento para a obtenção de híbridos que combinam características de ambas espécies originarias. Isto, sem dúvida, obriga à realização de estudos para encontrar materiais genéticos que maximizem as características desejadas com este fim (Gonzaga, 1983).

Neste sentido; tem sido feitas avaliações que mostram as vantagens da produção de pasta para papel com espécies de Eucalyptus, embora há sido estabelecido que existe uma grande variabilidade quanto ao comportamento das mesmas para tais usos. (Bosia et al., 1965; Seabra \& Oliveira, 1972; Pal \& Samuelson, 1976; Melo \& Paz, 1980; Kibblewhite et al., 1991; Mamers et al., 1991; Mezzomo et al. 1997; Cotterill \& Macrae, 1997).

Das espécies avaliadas, a madeira de $E$. globulus aparece como uma das melhores do ponto de vista do processo de obtenção de celulose. (Bosia et al., 1965; Chinchole \& Mehta, 1968; Hata et al., 1971; Seabra \& Oliveira, 1972; Pal \& Samuelson, 1976; Cáceres, 1983; Valente et al., 1992).

Esta espécie apresenta uma ampla distribuição quanto a sua adaptação, especialmente nas regiões da América do Sul onde as condições ecológicas são similares às de sua origem que é o sul do estado de Victoria e a ilha de Tasmânia, na Austrália.

Além disso, dentro desta espécie observa-se uma grande variação no comportamento das diferentes procedências quando são implantados em distintas zonas agroclimaticas de uma região. Esta variação ocorre tanto a nível de valores de crescimento como das características da madeira, encontrando-se 
genótipos com altos potenciais de crescimento e de rendimento de polpa até outros que, por sua baixa performance, indicam sua quase nula adaptação às condições desse sitio (Turner et al., 1983; Valente \& Furtado, 1993; Wallis et al., 1996; Beadle et al., 1996; Balmelli \& Resquin, 1999).

Em função desta variação encontrada, surge a necessidade de caracterizar as madeiras dos diferentes genótipos plantados para selecionar os melhores de acordo com seu crescimento, densidade da madeira e rendimento em celulose. Em relação a este ponto, existem alguns exemplos a serem considerados, como os da Portucel, onde na região ecológica atlântica portuguesa, a produção média anual espera-se que atinga os $40 \mathrm{~m}^{3}$ de madeira por hectare e uma produção de fibra kraft de 11 toneladas por hectare. Estes valores são mais relevantes ainda, tendo em conta que os valores iniciais de produção oscilavam de 20 a $30 \mathrm{~m}^{3}$ de madeira por hectare e por ano (Valente et al., 1993).

\subsection{Parâmetros da madeira de Eucalyptus relacionados à polpação}

\subsubsection{Densidade básica}

Quanto às características físicas da madeira, surge clara a importância de seu estudo para relacioná-la com os rendimentos em celulose e suas características físico/mecânicas (Barrichelo \& Brito, 1977). Nesse sentido, vários autores indicam à densidade como uma das características mais importante relacionadas a produção de celulose em várias espécies de Eucalyptus. (Barrichelo \& Brito, 1977; Gonzaga, 1983; Cáceres, 1983; Valente \& Furtado, 1983; Manfredi, 1985; Foelkel et al., 1992; Valente et al. 1992). 
Através da densidade básica ao se trabalhar com a madeira que é geralmente comprada em volume, é possível se conhecer seu peso seco obtendo-se com isso um adequado controle das operações industriais (Foelkel et al., 1971).

A densidade básica é uma característica complexa que está relacionada à anatomia e à química da madeira. Este parâmetro está correlacionado ao teor de celulose e extrativos da madeira, ao teor de vasos e parênquima e à espessura da parede (Foelkel, 1978). De acordo com este autor só com a determinação da densidade básica é possivel estimar se uma madeira tem potencial celulósico, apesar de que não possa se definir qual a qualidade da celulose resultante.

Por outro lado, tem se determinado que para muitas propriedades não basta trabalharmos apenas com a densidade, independentemente da espécie, pois madeiras de espécies diferentes com mesma densidade não são tecnologicamente ou anatomicamente semelhantes (Foelkel et al., 1992).

Segundo Pinho \& Cahen (1981), a densidade da madeira é um fator econômico importante para o cozimento. Por um lado deve ser considerada como um fator na produção de celulose obtida a partir de um tipo de madeira, em termos de rendimento por digestor ou por unidade de volume. Além disso, é sabido que a velocidade de impregnação da madeira pelo licor de cozimento são influenciados pela densidade e espera-se uma deslignificação mais rápida das madeiras menos densas.

Com madeiras mais densas, pode-se colocar uma maior carga num digestor por um determinado volume de digestor e portanto aumentar a produção de polpa, tanto num digestor tipo batch quanto por unidade de tempo 
num digestor contínuo (Mimms et al., 1993). Desta maneira, o cozimento da maior quantidade possível em massa da madeira por ciclo de digestor é economicamente vantajoso (MacDonald ${ }^{1}$ citaddo por Pinho \& Cahen, 1981). Neste sentido, Greaves \& Borralho (1996), determinaram que os custos de transformar madeira verde a polpa não branqueada, expressa em U\$S por tonelada de polpa seca, diminui com o incremento da densidade da madeira e o rendimento em polpa. A densidade tem um grande efeito sobre os custos do cozimento e um efeito não tão pronunciado sobre os custos de evaporação, de maneira que a altos custos de cozimento maior é a influência da densidade da madeira sobre os custos de polpação. Apesar que o rendimento em polpa tem um maior impacto do que a densidade sobre os custos de polpação, a densidade tem um maior potencial de variação genética que o rendimento e pode ser mais importante no melhoramento da polpação kraft.

A densidade da madeira varia entre espécies e dentro de árvores da mesma espécie. Esta variação depende da espessura da parede da célula e do tamanho da célula. Madeiras com paredes de maior espessura tem mais substância madeira e menos espaço vazio por unidade de volume do que madeiras com paredes mais finas. A qualidade da polpa e as operações posteriores, tal como o refino e a fabricação do papel, estão determinadas pela densidade da madeira usada. Fibras de paredes espessas (madeiras de alta densidade) produzem uma polpa bruta com fibras rígidas e alta taxa de drenagem da água. Fibras de paredes finas (madeiras leves) produzem polpas com fibras muito flexíveis, com uma alta resistência e alta densidade do papel (Mimms et al., 1993).

\footnotetext{
${ }^{1}$ MACDONALD,R.G. Pulp and paper manufacture. New York:McGraw-Hill, 1969.v.1
} 
Neste sentido existem uma série de trabalhos que mostram que embora a densidade básica seja bem correlacionada com a espessura da parede da parede celular há outros fatores importantes a se considerar, principalmente para Eucalyptus, que incidem nas propriedades da celulose. Dentre esses fatores mencionam-se: proporção e dimensão dos vasos da madeira, presença de extrativos, alta variabilidade no volume do parênquima na madeira e a alta variabilidade das características das próprias fibras entre espécies (Foelkel, 1974). Neste sentido Phillips \& Watson ${ }^{2}$ citados por Barrichelo \& Brito (1976), alertam que na opinião de alguns autores somente para espécies que possuem o mesmo número de vasos e mesmo volume de parênquima é que variações na densidade básica podem ser explicadas pela espessura da parede da fibra.

Geralmente, dá-se preferência às espécies de Eucalyptus de densidade média, entre 0,450 a $0,650 \mathrm{~g} / \mathrm{cm}^{3}$. Madeiras com densidades abaixo de $0,40 \mathrm{~g} / \mathrm{cm}^{3}$ mostram características indesejáveis, como alto teor de vasos de grandes dimensões ou alto teor de parênquima. Nesse caso, o consumo de madeira por tonelada de celulose atinge valores proibitivos. Por sua vez, são mais fáceis de deslignificar, devido a uma maior penetração do licor; o rendimento base peso é às vezes até melhor do que para as madeiras de densidade média; as resistências que dependem da ligação entre fibras , como a tração, estouro e dobras duplas, são excelentes enquanto que a resistência ao rasgo é prejudicada. As madeiras densas, com valores de densidade acima de $0,650 \mathrm{~g} / \mathrm{cm}^{3}$, são pouco usadas para a obtenção de celulose. Apesar de apresentarem algumas vantagens como o baixo consumo específico por tonelada de celulose e boas resistências ao rasgo tem uma série de desvantagens: mais difícil picagem, maior consumo de reagentes, alto teor de rejeitos e a resistência às dobras duplas é particularmente afetada (Foelkel,

\footnotetext{
${ }^{2}$ PHILLIPS,F.H.; WATSON, A J. Pulping studies on three eucalypt species from Western
} 
1978). A celulose obtida de madeira densa será composta de fibras de paredes espessas, as quais vão constituir num peso morto dentro da folha de papel já que existirão menos áreas de contato fibra-fibra e a ligação entre fibras será menor (Barrichelo \& Brito, 1976)

De acordo com Higgins et al ${ }^{3}$., citado por Barrichelo \& Brito (1976), avaliando espécies de Eucalyptus com uma faixa de densidade variando de 0,310 a $0,880 \mathrm{~g} / \mathrm{cm}^{3}$ observou-se que a relação entre a largura da fibra e a espessura de sua parede muitas vezes expressa como o Índice de Runkel é um fator de exerce influência decisiva sobre a densidade. Também determinou-se que para o Eucalyptus a estrutura dos vasos não interfere significativamente na relação existente entre as dimensões das fibras e a densidade básica. Dentre as relações existentes entre as dimensões das fibras foi observado que conforme aumentava o Índice de Runkel e o Índice de Boiler, também aumentava a densidade da madeira das espécies de Eucalyptus estudadas

Resultados de vários estudos com várias espécies de Eucalyptus mostram a relação entre a densidade da madeira e várias propriedades da polpa e do papel. Destes resultados pode-se concluir que existe uma correlação entre a densidade da madeira e os parâmetros mencionados além de que a densidade ótima foi próxima a $0,460 \mathrm{~g} / \mathrm{cm}^{3}$ devido a que com este valor foram obtidas os melhores resultados na polpa e no papel (Foelkel et al., 1975; Kramer, 1998). Neste sentido, Foelkel et al. (1992), avaliando várias espécies de Eucalyptus determinaram que algumas das principais propriedades na comercialização da celulose, como volume específico, resistência ao ar e absorção de água,

Australia., Melbourne, CSIRO 1962. 42p.

${ }^{3}$ HIGGINS,H.G. et al.. The density and srtcture of hardwoods in relation to paper surfece characteristics na dother properties. Melbourne: Appita 1973 56p. 
mostraram ser muito mais dependentes da densidade da madeira do que da espécie.

Segundo Barrichelo \& Brito (1976), até um certo limite no entanto a utilização de madeira densa pode apresentar algumas vantagens:

a) elas poderiam constituir em matérias-primas para a indústria de papeis finos, para escrita e impressão, onde um alto grau de deslignificação inter-fibras não é importante e onde propriedades como opacidade e volume específico aparente assumem maior significado.

b) Podem ser usadas em misturas de celulose colaborando para melhorar certas propriedades como resistência ao rasgo.

Segundo Higgins (1969), uma das vantagens das polpas de folhosas está referida à densidade da sua madeira. $\mathrm{O}$ autor afirma que se a densidade básica é demasiado alta, as propriedades de interligação entre as fibras do papel são negativamente afetadas, mas dentro do intervalo médio de densidade básica, as maiores valores podem ser vantajosos para os papéis finos fornecendo um volume adequado.

\subsubsection{Dimensões das fibras}

Os principais fatores a serem levados em consideração na fabricação do papel são principalmente a separação do material fibroso (madeira) em seus constituintes celulares (polpação), além da transformação das fibras em elementos flexíveis e colapsáveis (refino) e finalmente a morfologia das fibras (Bamber, 1985). 
As células mais importantes das folhosas são as fibras, os elementos de vaso e as células de parênquima. A fibra constitui, com relação à pasta e ao papel, o tipo de célula mais significativo. Estas células funcionam como tecido de suporte. São relativamente longas com um comprimento de 1 a $1,5 \mathrm{~mm}$ e uma espessura de 0,01 a 0,04 mm. Os vasos são de paredes finas e mais curtos, contendo uma grande quantidade de células abertas em cada extremo. Os vasos estão colocados um acima do outro formando tubos longos através dos quais são transportados a água e os nutrientes. Os mesmos tem um comprimento de 0,2 a $1,3 \mathrm{~mm}$ e um diâmetro de 0,02 a $0,3 \mathrm{~mm}$. $O$ número e diâmetro dos vasos exercem marcante influência na densidade da madeira e na qualidade da superfície de papéis de impressão. Por outro lado a penetração do licor também é amplamente dependente da existência da vasos (Stockan ${ }^{4}$, citado por Barrichelo \& Brito, 1976). As células do parênquima podem estar tanto em posição vertical quanto horizontal. Sua função é armazenar nutrientes e são uma fonte importante de extrativos. As células parenquimatosas são células curtas, de paredes finas estando sua importância ligada ao fato de contribuírem para uma redução na densidade básica da madeira. Embora se reconheça o efeito destas células na elevação do grau de refinação, sabe-se que para o Eucalyptus e dentro de certos limites, elas não exercem influência nas resistências das celuloses (Foelkel \& Barrichelo, 1975; Lima et al., 1981; Mimms et al., 1993).

É conhecido que a morfologia da fibra é de fundamental importância para a adaptabilidade de uma madeira para a polpação. Tanto a densidade de madeira quanto as propriedades de resistência do papel são afetadas pela mesma (Scaramuzzi, 1961).

\footnotetext{
${ }^{4}$ STOCKAM,L.G.. General properties of short fibred raw materials aans their influence on pulping.. In: (UNESCO/FAO. REGIONAL SYMPOSIUM ON PULP RESEARCH AND TECHNOLOGY IN THE MIDLE EAST AND NORTH AFRICA),1970. Proceedings
} 
Nas folhosas, as fibras para fabricar papel consistem principalmente de células libriformes mais as fibrotraqueídeos Em geral, as folhosas possuem quantidades menores de lignina e níveis maiores de celulose e hemiceluloses. (Jackson et al., 1989; Mimms et al., 1993). A porcentagem das fibras (englobando as fibras libriformes e os fibrotraqueídeos) no Eucalyptus é de $65 \%$, de vasos é de $17 \%$ e células do parênquima $18 \%$ (Barrichelo \& Brito, 1976).

Em se tratando de dimensões de fibras, é necessário destacar que a determinação das mesmas é muito importante nos processos de estudos e produção de celulose. Com essas determinações, podem ser caracterizadas certas propriedades que a celulose e o papel apresentarão quando forem obtidos e colocados em uso. Os parâmetros geralmente considerados nos estudos tecnológicos das fibras são definidos por quatro dimensões principais: 0 comprimento da fibra (C), a largura da fibra (L), o diâmetro do lume da fibra (DL) e a espessura da parede da fibra (E). A partir desses valores, podem ainda serem calculados coeficientes relacionando as dimensões entre si (Barrichelo \& brito, 1976). Estes índices são o Índice de Runkel, Fração parede, Índice de enfeltramento e Coeficiente de flexibilidade.

Em relação a este índices, de acordo com Paula \& Alves (1989), as madeiras de boa qualidade para a produção de papel são as que possuem alta proporção de fibras de fração parede baixa (paredes finas), coeficientes de rigidez a partir de $50 \%$. Índice de Runkel até 2 e peso específico até $0.6 \mathrm{~g} / \mathrm{cm}^{3}$. Fibras com baixo coeficiente de flexibilidade possuem alta resistência ao rasgo e à tração. Fibras com coeficiente de flexibilidade alto apresentam baixa resistência à tração, resultando que em polpas refinadas a partir de fibras curtas existem mais cruzamentos de fibras e mais áreas de ligações disponiveis por 
unidade de peso em relação à polpa de fibras longas. O coeficiente de rigidez e o índice de Runkel indicam o grau de colapso que sofrem as fibras durante o processo de fabricação do papel. Segundo estes autores, quanto mais baixo o índice de Runkel e mais alto coeficiente de rigidez, maior será a grau de colapso das fibras, e portanto maior ligadura entre as mesmas o que produz papéis mais resistentes ao rasgo e ao estouro. Em resumo, pode-se dizer que fibras com índice de Runkel abaixo de 1 e coeficiente de rigidez acima de $60 \%$ são considerados de. boa qualidade para produção de papel.

Segundo Melo 5 citado por Barrichelo \& Brito (1976), é obvio que não pode-se admitir que uma dimensão isolada de uma fibra ou o cálculo de apenas uma relação entre as dimensões possam dar elementos para se apontar uma propriedade do papel. De acordo com estes mesmos autores em relação ao comprimento, alguns anos atrás acreditava-se que o mesmo era o mais importante fator na determinação de algumas propriedades da polpa ou do papel. Atualmente, sabe-se que o comprimento, ainda que importante, não pode ser tomado isoladamente sem que outros parâmetros sejam considerados conjuntamente. Apesar de que é evidente que para a fabricação de papel são necessárias fibras alongadas, não está demonstrado que a esbeltez seja um fator imprescindível. Wardrop \& Dadswell ${ }^{6}$ citados por Bamber (1985), avaliando a relação entre o comprimento da fibra e o diâmetro com as propriedades do papel concluíram que esta relação não foi um bom indicador da qualidade do papel.

As fibras de Eucalyptus são geralmente definidas como rígidas, de parede espessa e portanto pouco flexíveis. A relação entre a espessura da

\footnotetext{
${ }^{5}$ MELO,R.J. Identificação micrográfica de fibras celulósicas. contribuição para a nálises de pastas e papéis. Angola: Instituto de Investigação Agronômica, 1973 (Série Científica,31)

${ }^{6}$ WARDROP A.B. ;DADSWELL, H.E. Appita v.17,p.146, 1964.
} 
parede da fibra e o diâmetro destas varia de 0,7 a 1,5 de acordo com o índice de Runkel (Gamoeda, 1988).

O tamanho reduzido das fibras combinado com sua rigidez, baixa compressabilidade e adesão produz durante os processo de produção de papel uma estrutura de folha mais aberta, com distâncias mais curtas entre os pontos de contato resultando numa boa formação, maciez superficial, alta absorvidade, excelente volume e opacidade (Barrichelo \& Brito, 1976.).

A resistência da fibra numa madeira normal é atribuída diretamente à espessura da parede da célula e sem dúvida, em particular à camada S2. Devido a que os Eucalyptus em geral tem células de paredes espessas em relação a outras espécies, espera-se que as fibras possuam boa resistência (Bamber, 1985).

A influência do comprimento da fibra nas resistências do papel é explicado pelo fato de que nas fibras longas há menor possibilidade destas se separarem da estrutura do papel quando esta é submetido a um esforço. Por outro lado com um maior comprimento da fibra, durante o processo de refinação a capacidade de desfibramento é aumentada, aumentando consequentemente a capacidade de ligações entre fibras. A espessura da parede da fibra tem sua influência em função de uma maior ou menor capacidade de sofrer colapso (Barrichelo \& Brito, 1976).

As fibras de paredes delgadas tem uma maior capacidade de sofrerem colapso e adquirirem a forma de fita durante os processos de compressão na formação da folha e desse modo aumentando as resistências do papel pela maior capacidade ligação entre fibras. As fibras de paredes espessas 
não sofrem colapso e mantém suas formas tubulares na estrutura do papel resultando numa diminuição de suas resistências (Wardrop ${ }^{7}$ citado por Barrichelo \& Brito, 1976).

O comprimento da fibra surge como o principal fator relacionado à resistência ao rasgo. Vários trabalhos mostram uma forte dependência desta propriedade do papel sobre o coeficiente de enfeltramento (relação comprimento/espessura da fibra) estabelecendo que o comprimento das fibras não esteja por baixo de determinados valores $(0,7$ a $0,9 \mathrm{~mm})$. A espessura da parede das fibras parece ter uma grande importância em outras propriedades de resistência. As fibras de paredes finas de grandes cavidades colapsam formando fitas durante a formação da folha dando uma grande área de interligação resultando em folhas resistentes. Fibras de paredes espessas, ao contrário, não colapsam mantendo sua forma tubular fazendo que não ocorra uma fácil ligação produzindo polpas de baixa resistência. Só a resistência ao rasgo em alguns casos parece ser incrementada por uma maior espessura da parede. A relação espessura da parede/raio do lume, portanto, deve ser menor a 1 (Scaramuzzi, 1961).

Quanto a relação da morfologia das fibras de madeira de folhosas sobre as propriedades do papel podem se estabelecer várias considerações gerais (Watson \& Dadswell, 1961; Tamolang \& Wangaard, 1961; Wangaard, 1973; Foelkel \& Barrichelo, 1975):

A resistência à tração tem mostrado uma boa correlação positiva com o comprimento da fibra e o diâmetro do lume e por sua vez uma correlação negativa com a espessura da fibra. Dos coeficientes obtidos a partir das

\footnotetext{
${ }^{7}$ WARDROP,AB. Fiber morphology and papermaking. Atlanta:TAPII, 1969.
} 
dimensões das fibras há uma correlação positiva desta propriedade com a fração parede e o coeficiente de flexibilidade e uma correlação negativa com o índice de Runkel.

A resistência ao rasgo pode apresentar correlação negativa com a largura da fibra e a espessura da parede e uma correlação positiva com o diâmetro do lume e comprimento da fibra. Tem se observado, em geral, que esta propriedade também esta positivamente correlacionada com o coeficiente de flexibilidade, índice de enfeltramento, fração parede e índice de Runkel.

A resistência ao arrebentamento mostra uma correlação positiva com o comprimento da fibra e diâmetro do lume e uma correlação negativa com a largura da fibra e a espessura da parede. Também existe uma correlação positiva com o índice de Runkel.

O peso específico está positivamente correlacionado com a espessura da parede e também com o coeficiente de flexibilidade.

\subsubsection{Principais características físicas das polpas de Eucalyptus}

Os valores de rendimento, permitem observar diferenças notórias no comportamento das espécies (Figura 4). O E.globulus caracteriza-se por apresentar o maior rendimento em celulose. Estes valores são um reflexo do teor de lignina o qual de modo geral tem uma tendência inversa à do rendimento em celulose. 


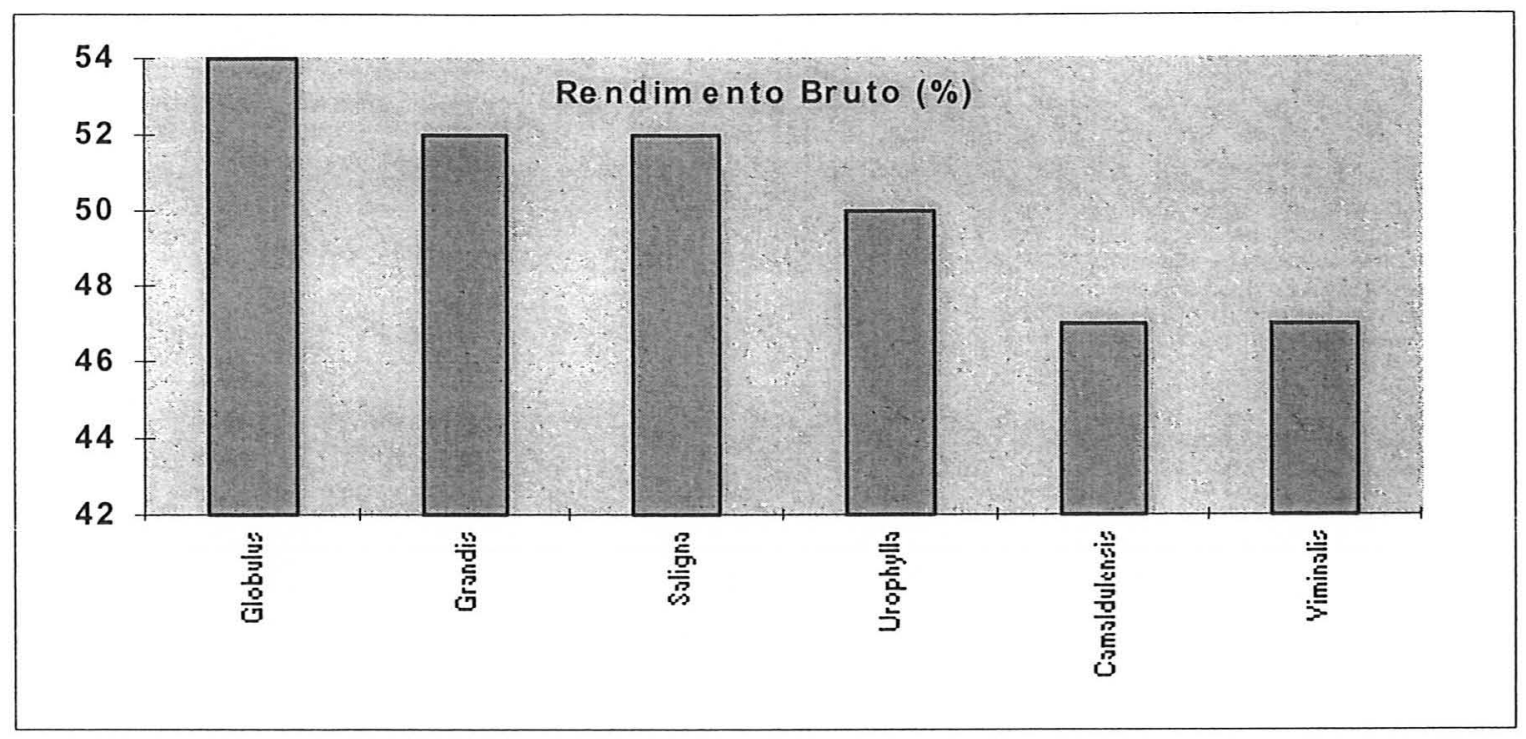

Figura 4 - Rendimento em celulose de várias espécies de Eucalyptus

Fonte: FPL, 1958; Ferreira et al., (1997); Foelkel et al., (1975);

Barrichelo \& Foelkel (1976 e 1974); van Wyk \& Gerischer (1994);

Gonzaga et al., (1984); Barrichelo \& Brito (1976); Barrichelo \&

Brito (1983); Texeira \& Soares (1992); Queiroz (1972);

Barrichelo \& Brito (1976).

Quanto aos valores de resistência das polpas, observa-se que 0 aumento do refino melhora os valores para todas as espécies (Figura 5, 6 e 7). De uma maneira geral, de acordo aos valores médios reportados na literatura, exceto os valores de índice de rasgo, as propriedades mecânicas correspondentes à celulose de E.globulus superam aquelas obtidas para a polpa das demais espécies nos dos níveis de refino apresentados 30 e $45^{\circ} \mathrm{SR}$ (cores vermelho e azul, respectivamente). Esta superioridade do E.globulus poderia ser explicada, dentre outras razões, pelo menor teor de lignina e principalmente pelo alto teor de hemiceluloses desta espécie (Queiroz, 1972). Segundo 
Ratnieks $^{8}$ citado por Ferreira et al. (1997), as polpas que desenvolvem resistências durante o refino são aquelas com maior teor de hemiceluloses.

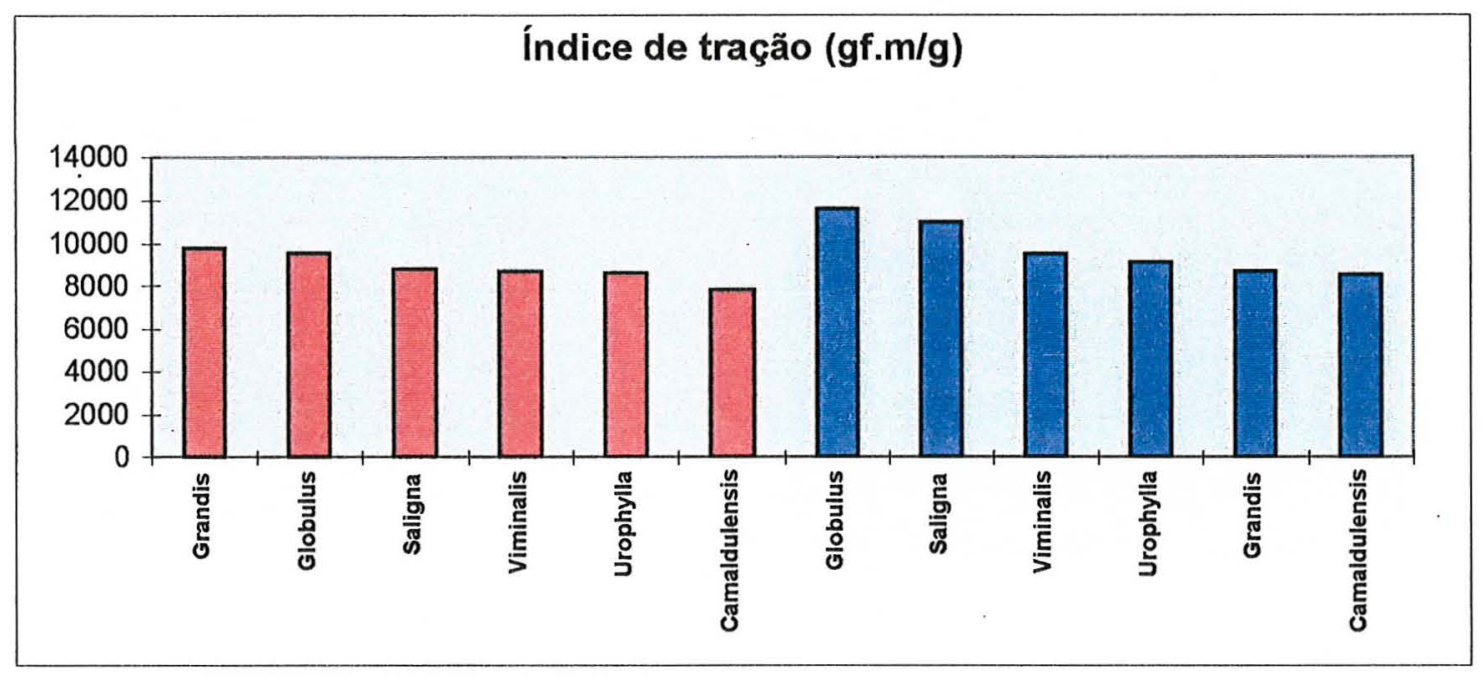

Figura 5 - Índice de tração de várias espécies de Eucalyptus para 30 e $45^{\circ} \mathrm{SR}$

Fonte: Ferreira et al., (1997); Foelkel (1974); Foelkel et al., (1975); Barrichelo \& Foelkel (1976); van Wyk \& Gerischer (1994); Gonzaga et al., (1984); Barrichelo \& Brito (1976); Barrichelo \& Brito (1983); Texeira \& Soares (1992); Queiroz (1972); Barrichelo \& Brito (1976); Foelkel et al., (1977)

\footnotetext{
${ }^{8}$ RATNIEKS,E. Alterações no refino e no teor de hemiceluloses da polpa. Guaíba: Rocel, 1983.14p. (Relatório Técnico 630).
} 


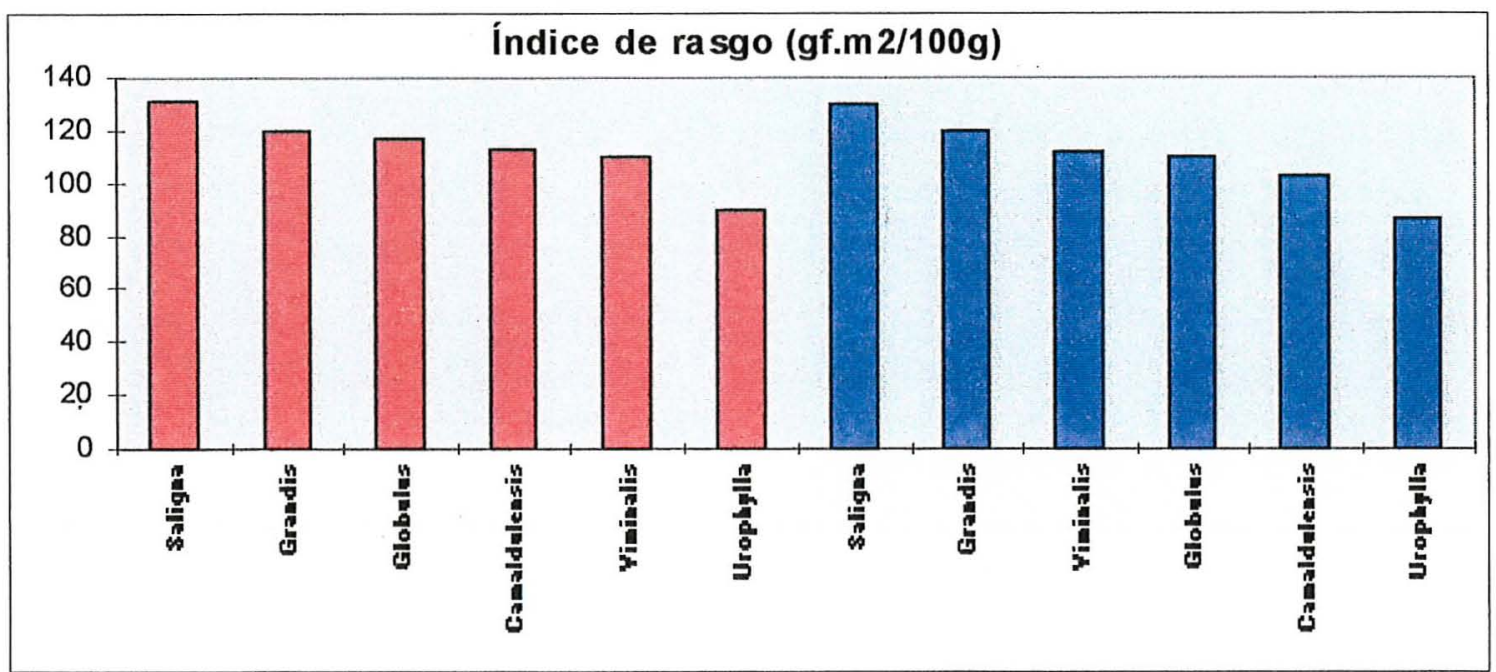

Figura 6 - Índice de rasgo de várias espécies de Eucalyptus para 30 e $45^{\circ} \mathrm{SR}$

Fonte: Ferreira et al., (1997); Foelkel (1974); Foelkel et al., (1975);

Barrichelo \& Foelkel (1976); van Wyk \& Gerischer (1994); Gonzaga et al., (1984); Barrichelo \& Brito (1976); Barrichelo \& Brito (1983);

Texeira \& Soares (1992); Queiroz (1972); Barrichelo \& Brito (1976);

Foelkel et al., (1977)

Para uma dada espécie, a maior remoção de hemiceluloses durante o processo de polpação caracteriza um maior número de fibras por unidade de peso da polpa, e vice-versa. $\mathrm{O}$ alto conteúdo de hemiceluloses favorece a ligação entre fibras, enquanto que o menor conteúdo das mesmas favorece as propriedades não dependentes da ligação tais como resistência ao rasgo. A importância das hemiceluloses, no desenvolvimento de propriedades de resistência, correlaciona-se com a fibrilação. Os finos gerados pela ação de refino são um fator importante no desenvolvimento de resistência à tração, e esta ação é ligada à hemicelulose. Celuloses com maior teor de hemiceluloses de cadeias mais amorfas são mais sujeitas ao inchamento pela água e isso igualmente favorece o refino. 


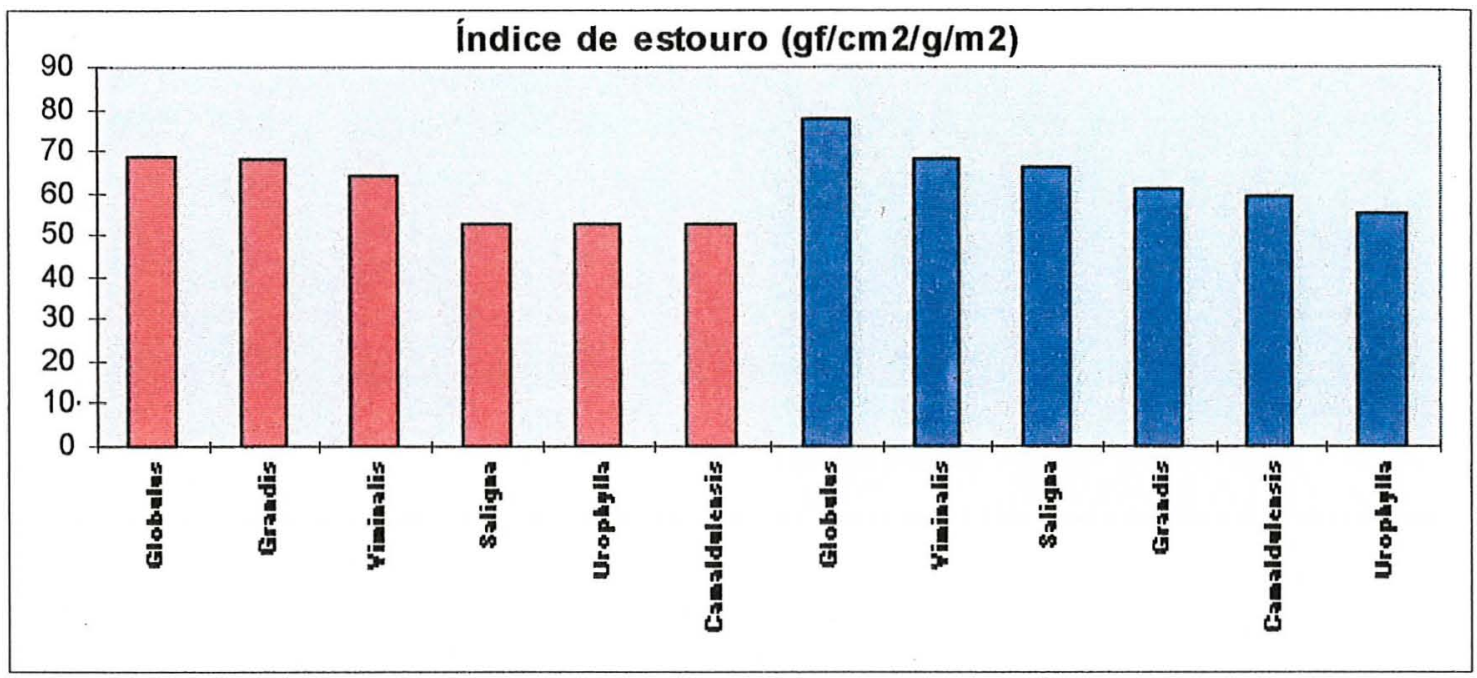

Figura 7 - Índice de estouro de várias espécies de Eucalyptus para 30 e $45^{\circ} \mathrm{SR}$ Fonte: Ferreira et al., (1997); Foelkel (1974); Foelkel et al., (1975); Barrichelo \& Foelkel (1976); van Wyk \& Gerischer (1994); Gonzaga et al., (1984); Barrichelo \& Brito (1976); Barrichelo \& Brito (1983); Texeira \& Soares (1992); Queiroz (1972); Barrichelo \& Brito (1976); Foelkel et al.,(1977)

A densidade da madeira e o número de permanganato (teor de lignina residual na polpa) também explicariam os menores valores de resistência ao rasgo (Foelkel, 1974).

Outro dos fatores que podem estar influenciando nestes valores são a maior capacidade de interligação das fibras baseado na maior flexibilidade e menor rigidez das mesmas. É bem sabido que fibras que apresentam altos índices de Runkel e frações paredes e baixos coeficientes de flexibilidade mostram-se rígidas e pouco flexíveis na formação do papel, prejudicando as propriedades que dependem da interligação das fibras (resistência à tração e ao estouro) e melhorando a resistência ao rasgo (Foelkel et al.,1975 ). 


\subsubsection{Composição química}

A composição química da madeira de Eucalyptus pode ser sintetizada na tabela 1 , sendo que quantitativamente eles ocorrem nas diferentes espécies com uma variação considerável.

Tabela 1. Composição química quantitativa média da madeira de Eucalyptus

\begin{tabular}{ll}
\hline Componentes & $\%$ \\
\hline Celulose & $40-55$ \\
Hemiceluloses & $20-40$ \\
Lignina & $15-25$ \\
Extrativos & $1-5$ \\
Compostos minerais (cinzas) & $0,1-1,0$ \\
\hline
\end{tabular}

Fonte: Barrichelo \& Brito, 1976.

Na tabela 2, é apresentada a composição química das diferentes espécies de Eucalyptus as quais afetam as características da polpação. Destes valores, pode-se dizer que existe uma ampla variação principalmente nos teores de celulose e lignina embora todas as espécies possam ser submetidas a processos de polpação química com rendimentos razoáveis em polpa. Contudo, algumas espécies possam requer condições de cozimento mais drásticas (Palmer et al., 1990). 
Tabela 2. Composição química quantitativa das madeiras de várias espécies de Eucalyptus

\begin{tabular}{lcccc}
\hline & $\begin{array}{c}\text { Celulose } \\
(\%)\end{array}$ & $\begin{array}{c}\text { Holocelulose } \\
(\%)\end{array}$ & $\begin{array}{c}\text { Lignina } \\
(\%)\end{array}$ & $\begin{array}{c}\text { Pentosanas } \\
(\%)\end{array}$ \\
\hline E.globulus & 45 & $74-82$ & $20-23$ & 21 \\
E.grandis & $54-56$ & $70-83$ & $23-32$ & $15-24$ \\
E.saligna & $46-61$ & $73-81$ & $19-35$ & $12-17$ \\
E.urophylla & 53 & $72-85$ & $24-28$ & $14-19$ \\
E.camaldulensis & 50 & 71 & $27-30$ & $14-17$ \\
E.viminalis & $52-56$ & 73 & $23-25$ & $17-19$ \\
\hline
\end{tabular}

Fonte: Texeira \& Soares (1992); Barrichelo \& Brito (1983) e (1976); Queiroz (1972); Barrichelo \& Foelkel (1976); Foelkel et al., (1975); Palmer et al., (1990); Ferreira et al., (1997); Foelkel et al., (1977); Cáceres (1983); Gamoeda (1988).

\subsubsection{Celulose}

De acordo com os valores apresentados anteriormente, pode-se notar que a celulose é o principal constituinte da madeira. Isto também é observado na pasta obtida da madeira, com a celulose determinando a maioria de suas propriedades. A celulose exerce influência na resistência da fibra individual, nas ligações entre fibras e associada com as hemiceluloses determina as características da pasta celulósica em termos de rendimento e de resistência (Barrichelo \& Brito, 1976).

Quanto à relação entre o rendimento em celulose e a densidade básica de madeira, segundo Foelkel, s/d, podem serem encontrados três diferentes modelos na literatura: modelo 1: autores que admitem a existência 
de uma relação linear positiva entre o rendimento em polpa por unidade do digestor e a densidade da madeira; modelo 2: autores que admitem uma relação linear positiva entre o rendimento em polpa por unidade do digestor e a densidade da madeira considerando uma única espécie e modelo 3: similar à anterior mas trabalhando com várias espécies as quais tem similares características morfológicas na maioria dos casos de mesmo gênero taxonômico. Por outro lado, alguns autores sugerem cautela para estabelecer correlações entre as propriedades da celulose e a densidade da madeira. Isto se deve a que a densidade da madeira, apesar de estar correlacionada positivamente com a espessura da parede, existem outros fatores os quais podem influencia-la, principalmente para Eucalyptus.

\subsubsection{Lignina}

A lignina é uma substância amorfa que junto com a celulose forma as paredes das células da madeira. Ë um material de cimentação entre as células e fornece resistência mecânica à madeira. A lamela média, a qual consiste principalmente de lignina, mantém as células juntas e da a estrutura da madeira. As paredes das células também contem lignina, que junto com a hemiceluloses formam o cimento no qual são arranjadas as microfibrilas da celulose (Mimms e al., 1993).

A lignina como segundo componente da madeira do ponto de vista quantitativo, representa um composto indesejável para a produção de celuloses químicas. Durante as processos de cozimento e branqueamento o objetivo é removê-la causando o menor dano possível às fibras (Barrichelo \& Brito, 1976). 
Para que possam ser obtidas as características exigidas para uma polpa química, é necessário que seja removida grande parte da lignina existente na lamela média, e também na parede secundária. Tem sido determinado que durante a polpação kraft, nos estados iniciais do cozimento, a lignina é principalmente removida da parede celular. Quando é atingido perto de $50 \%$ da deslignificação, a lamela média e as áreas dos cantos das células, que são altamente lignificadas, são fortemente atacadas, permanecendo no final do cozimento, uma lignina residual na parede secundária e na lamela média (Gomide, 1979).

O menor conteúdo de lignina das folhosas pode resultar num menor consumo de reagentes na polpação e uma subsequente redução do tempo de cozimento quando comparadas com as coníferas (Higginns, 1969).

De modo geral as madeiras que contem menores teores de lignina são mais facilmente deslignificadas no cozimento e consumem menor quantidades de reagentes no branqueamento (Barrichelo \& Brito, 1976). Isto é importante com espécies contrastantes tais como o E.globulus e E.camaldulensis quanto à facilidade de deslignificação e em relação à preservação das hemiceluloses, determinada pelo alto conteúdo de pentosanas existente na primeira destas espécies. Quando o conteúdo de lignina na madeira é elevado, só é possível uma deslignificação com um inevitável deterioro e perdida de material celulósico. Para manter o rendimento em um nível aceitável, é necessário tolerar um excesso de lignina na polpa, que vai refletir na dificuldade do branqueamento (Queiroz, 1972).

De acordo com Watson, 1961, é reconhecido que um alto teor de lignina na polpa afeta negativamente as propriedades do papel, principalmente 
as associadas com a ligação das fibras. Hall ${ }^{9}$ citado por este autor sugere que existe um conteúdo ótimo de lignina para maximizar as propriedades de resistência. Resultados similares foram obtidos por Ona et al. (1995), avaliando espécies de Eucalyptus.

A lignina que permanece na celulose após os processos de cozimento colabora para que a fibra seja mais rígida, resultando no caso de altos teores, em papéis de baixa resistência e alta opacidade (Barrichelo \& Brito, 1976).

\subsubsection{Extrativos}

A madeira geralmente contem pequenas quantidade de várias substâncias que são chamadas "extrativos". Estas substâncias podem serem extraídas da madeira tanto por água quanto por solventes orgânicos tais como álcool ou éter. Os ácidos graxos, resinas, ceras, terpenos e compostos fenólicos são alguns dos grupos que compõem os extrativos. A maioria deles são recuperados na polpação kraft. Alguns dos extrativos menos solúveis podem causar problemas de pitch na polpação kraft e na fabricação do papel. $O$ pitch consiste de pequenos agregados de extrativos não dissolvidos (Mimms et al., 1993).

Os extrativos podem exercer vários tipos de influência na fabricação de polpas celulósica e de papel, dentre os quais destacam-se: redução no rendimento, aumento no consumo de reagentes, inibição das reações de polpação, corrosão do equipamentos, propriedades da polpa e a recuperação do licor consumido (Hillis, 1962; D'Almeida, 1981).

\footnotetext{
${ }^{9}$ HALL, G.A. World's Paper Trade .91, p.1340, 1929.
} 


\section{MATERIAL E MÉTODOS}

\subsection{Material}

A espécie utilizada foi o Eucalyptus globulus ssp globulus com árvores pertencentes a um ensaio de avaliação de procedências e progênies provenientes da Austrália, instalado na primavera do ano 1994 no departamento de Tacuarembó, Uruguai. As coordenadas geográficas do experimento são: latitude: $31^{\circ} 40^{\prime} \mathrm{S}$, longitude: $56^{\circ} 00^{\prime}$ e altitude: 100 metros sobre o nível do mar. O material geológico são areniscas de Tacuarembó e os solos dominantes são Luvisoles Ocricos, muito profundos, de cor pardo amarelado escuro, textura arenoso - franca, bem drenados e fertilidade extremamente baixa.

O mesmo é composto por 15 procedências e cada uma das quais possui um numero variável de progênies, totalizando 70 materiais genéticos.

O delineamento estatístico usado na instalação é de parcelas divididas, onde as procedências são as parcelas e as progênies as subparcelas. Estas últimas estão formadas por 10 plantas em linha. O espaçamento é 3 metros entre linhas e 2,5 metros entre plantas. Na implantação do experimento, não foram utilizados fertilizantes. 


\subsection{Métodos}

\subsubsection{Amostragem}

Para os objetivos desta dissertação foram selecionados as melhores procedências e, dentro destas, as melhores progênies, segundo a ultima avaliação de crescimento realizada no ano de 1999. Em função disto, como primeiro passo, procedeu-se o ranking,em ordem decrescente, de todas as procedências em avaliação de acordo a seu Valor Genético (BV). Na Tabela 3 são apresentadas as caracteríticas das procedências de Eucalyptus globulus que foram escolhidos para o presente trabalho

Destes dados observa-se que a maioria dos origens procedem da ilha de Tasmânia, salvo três que procedem do sul do estado de Victoria.

Um dos primeiros pontos a definir foi o número de procedências a avaliar e dentro destes o número de progênies. Neste sentido, considerou-se que 4 ou 5 famílias seria um número bastante representativo de uma procedência, sendo que 3 progênies poderia ou não, dependendo da variação existente entre as mesmas. Um número inferior a este foi considerado como muito pouco representativo de uma procedência não sendo recomendável sua avaliação. Como previamente não se sabia qual é a variação existente, optou-se por avaliar entre 4 a 5 progênies por procedência.

Em relação ao número de árvores pôr progênies, ocorre algo similar quanto à possível variação existente entre árvores. Por isso, foram coletados 5 árvores pôr progênie. De todas as arvores que compõem cada progênie, foram 
escolhidos aqueles que estavam próximos à media de DAP segundo a ultima avaliação de crescimento.

Em função disto, não foram consideradas nesta avaliação, as procedências que estão compostos por menos de 4 ou 5 progênies e as que apresentam um baixo crescimento. A única excepção a esto ocorreu com a procedência número 1 que apesar de estar composta por só três progênies é dos poucos que procedem do estado da Victoria, com a particularidade que é reconhecido em vários países como uma das melhores fontes de semente desta espécie.

Tabela 3. Lista de materiais genéticos instalados no ensaio de procedências/progênies no Uruguai

Código Localidade Latitude Longitude Altitude Número de progênies

\begin{tabular}{cllrrcc}
\hline 1 & Jeeralangs-Yarram. & S. VIC & 38.24 & 146.31 & 225 & 3 \\
12 & Pepper Hill Road. & N.TAS & 41.38 & 147.51 & 540 & 5 \\
10 & N Cape Barren Island. & E.BASS & 40.22 & 148.13 & 20 & 4 \\
14 & Lake Leake RD Swansea. & N. TAS & 42.01 & 147.58 & 300 & 5 \\
21 & Geeveston Area. & S. TAS & 43.13 & 146.54 & 360 & 5 \\
16 & Moogara. & C.TAS & 42.47 & 146.55 & 500 & 5 \\
8 & Flinders Island. & E.BASS & 40.06 & 148 & 15 & 5 \\
\hline
\end{tabular}

Nota: VIC: Estado de Victoria, Austrália TAS: Ilha da Tasmânia, Austrália 
Em resumo, as procedências avaliadas foram: 1 (VIC); 8 (Ilha Flinder); 10 (Ilha Cape Barren); 12 e 14 (NE TAS); 16 (Centro TAS) e 21 (S TAS), o que permite ter um amostragem relativamente boa da área de distribuição natural desta espécie. Neste caso, das procedências 8 e 16 escolheram-se as 5 progênies de melhor crescimento.

De cada árvore, cortaram-se 5 discos a 0,25, 50, 75 y $100 \%$ da altura comercial, correspondendo esta última a um diâmetro com casca de aproximadamente 6 centímetros.

Como resultado de todo isto, o número final de amostras a analisar surgiu de: 32 progênies das procedências antes mencionadas, vezes 5 árvores de cada uma, vezes 5 discos de cada árvore, o que resulta num total de 800 amostras de discos.

As variáveis ensaiadas foram:

- densidade básica

- comprimento, largura, diâmetro do lume e espessura das paredes das fibras

- conteúdo de holocelulose, lignina e extrativos

- rendimento em celulose e número kappa

- propriedades físicas e mecânicas da celulose

Cada um dos discos foi divido em quatro cunhas aproximadamente iguais. Duas destas foram usadas para medir densidade e as outras duas para medir propriedades anatômicas das fibras, composição química e rendimento em celulose. Para as determinações das propriedades anatômicas usaram-se 
pequenas fatias das cunhas usando o restante da amostra para fazer os cozimentos.

A densidade básica foi determinada em cada uns dos discos. Para determinar o rendimento em celulose, foram picadas manualmente as 25 cunhas que formavam cada progênie ( 5 árvores vezes 5 discos de cada), daí formou-sev uma amostra composta misturando tudo o material picado e finalmente tomou-se uma amostra de aproximadamente $350 \mathrm{~g}$. Procurou-se obter cavacos com aproximadamente as seguintes dimensões: $25 \mathrm{~mm}$ de comprimento (em função do tamanho do disco) e $4 \mathrm{~mm}$ de espessura. A largura foi variável dependendo do diâmetro dos discos. Para determinar a quantidade de cavaco a ser picada em cada um dos discos das diferentes alturas em cada uma das progênies, seguiu-se o seguinte procedimento:

1) pesaram-se todos os discos correspondentes a cada uma das alturas

2) calculou-se a porcentagem do peso em gramas de cada uma das alturas em relação ao peso de todos os discos.

Como este valor de porcentagem, foi estimada a quantidade de cada disco a ser picada de forma de completar os 350 gramas mencionados anteriormente.

Da amostra composta de cada uma das progênies, foram tirados aproximadamente 250 gramas para fazer os cozimentos e o restante foi moído para determinar o teor de lignina, extrativos totais e holoceluloses. Com as amostras provenientes de cada progênie, fizeram-se duas repetições de cada cozimento. Com a polpa obtida destes cozimentos, foram confeccionadas as folhas a partir das quais foram feitos os testes mecânicos. 
Das amostras compostas de cada progênie foram tiradas pequenas fatias dos cavacos para medir as dimensões das fibras.

\subsubsection{Densidade da madeira}

Foi utilizado o método da balança hidrostática para a determinação das densidades básicas dos discos a partir dos quais calculou-se a média das árvores e as médias das progênies e procedências. $O$ valor de densidade de cada disco foi determinado a través da seguinte relação:

$\mathrm{Db}=\mathrm{ps} /($ pú $-\mathrm{pi})$

onde

ps - peso seco em estufa a $103 \pm 2^{\circ} \mathrm{G}$

pu - peso úmido

pi - peso imerso na água

Este ensaio é baseado na norma ABCP M 14/70. O valor de densidade médio de cada árvore foi calculado conforme a equação:

$$
D_{e}=\frac{\left(D_{1}^{2}+D_{2}^{2}\right)\left(D e_{1}+D e_{2}\right)+\left(D^{2} 2+D^{2} 3\right)\left(D e_{2}+D e 3\right)+\left(D_{3}^{2}+D_{4}^{2}\right)\left(D e_{3}+D e_{4}\right)+\left(D_{4}^{2}+D_{5}^{2}\right)\left(D e_{4}+D e_{5}\right)}{2\left(D_{1}^{2}+D_{5}^{2}\right)+2\left(D_{2}^{2}+D_{3}^{2}+D_{4}^{2}\right)}
$$

Onde $D_{1}, D_{2}, D_{3}, D_{4}, D_{5}$ são os valores de diâmetro sem casca e $\mathrm{De}_{1}, \mathrm{De}_{2}, \mathrm{De}_{3}, \mathrm{De}_{4}, \mathrm{De}_{5}$ a densidade básica para as alturas de $0,25,50,75,100 \%$, respectivamente. 


\subsubsection{Dimensões das fibras}

Através de microscopia ótica foram realizadas as seguintes medições nas fibras: comprimento, largura, diâmetro do lume e espessura das paredes. Estas medições foram feitas macerando as mostras provenientes de cada uma das progênies para a individualização dos elementos anatômicos. Para isto, colocaram-se os fragmentos de madeira, tirados dos cavacos, em tubos de ensaio com uma solução nítrica-acética quente formada por cinco partes de ácido acético glacial e uma parte de ácido nítrico concentrado. 0 material foi lavado com água destilada para remover a solução ácida, tomando-se pequenas amostras para a observação. O comprimento das fibras (C) foi medido com 0 micro projetor. A largura (L) e o diâmetro do lume (DL) foram medidas no microscópio ótico. A espessura da parede $(E)$ foi calculada pela diferença entre a largura e o diâmetro do lume. De cada progênie foram medidas as dimensões de 50 fibras. Com estes valores foram calculados os seguintes índices:

1) Índice de Runkel: calculado como o quociente $2 E / D L$

2) Fração parede: expressa a relação entre (2E/L)*100

3) Índice de enfeltramento: expressa a relação $\mathrm{C} / \mathrm{L}$.

4) Coeficiente de flexibilidade: definida como (DL/L)*100

\subsubsection{Composição quimica da madeira}

Utilizando métodos analíticos convencionais, as madeiras foram analisadas quanto aos teores de lignina e extrativos totais. A amostragem e as análises foram feitos de acordo com os métodos da TAPPI dependendo do elemento a medir. Para determinar lignina, o método usado foi segundo a TAPPI 
T13 $\mathrm{m}$ - 54 e para os extrativos o método foi segundo a TAPPI T6 $\mathrm{m}-59$. O teor de holcelulose foi determinado por diferença segundo a expressão:

100 - (teor de lignina + teor de extrativos totais)

\subsubsection{Producão de polpa}

Foi utilizado o processo sulfato e as condições de deslignificação foram preestabelecidas e determinadas pêlos seguintes parâmetros: álcali ativo $15 \%$ como Na20, 25\% de sulfidez; 170 oC de temperatura máxima; 90 minutos até atingir a máxima temperatura, 45 minutos a máxima temperatura procurando obter um fator $\mathrm{H}$ de 800 . A relação licor-madeira foi de 4 para 1 . Para isto, foi utilizado um digestor rotativo, com capacidade para fazer 8 cozimentos em cápsula de $200 \mathrm{ml}$. O mesmo é aquecido eletricamente, usando 8 litros de água como veículo de transferência de calor.

De cada uma das progênies foram cozidas 80 gramas de madeira absolutamente seca. Com os valores do percentagem seco foram calculados as quantidades de sulfeto de sódio, hidróxido de sódio e água de acordo com as condições já mencionadas no parágrafo anterior. Com o peso da polpa obtida dos cozimentos e porcentagem seco das mesmas foram determinados os rendimentos brutos. Este foi calculado como a relação, expressada em percentagem, entre o peso da celulose e o peso da madeira usada, ambas totalmente secas, de acordo com a seguinte relação:

Rendimento bruto $(\%)=$ Peso da polpa bruta * \% seco da polpa * 100 Peso seco da madeira

O rendimento depurado (passando a polpa bruta por um classificador 
de fibras) foi calculado como o quociente, expressada em percentagem, entre o peso da celulose bruta descontando o peso do rejeito e o peso da madeira utilizada, todos em base seca:

Rendimento depurado $(\%)=$ Peso da polpa seca - peso seco dos rejeitos $* 100$ Peso seco da madeira

O rejeito foi calculado como a relação entre o peso seco dos rejeitos em relação ao peso seco da madeira usada.

O número kappa foi determinado de acordo a uma modificação da norma TAPPI T-236 cm 85-1998. Aos efeitos de comparar os resultados de rendimento depurado e número kappa das progênies foi calculado a relação rendimento depurado/número kappa.

\subsubsection{Ensaios das polpas}

Para estudar as propriedades físicas e mecânicas das polpas foi feita uma amostra de cada uma das procedências, formada pela mistura em partes iguais das polpas de cada uma das progênies, considerando o porcentagem seco de cada uma delas. As polpas provenientes da deslignificação Kraft das procedências foram refinadas em moinho centrífugo Jokro Mühle, 150rpm, utilizando $16 \mathrm{~g}$ s.e. por panela, a uma consistência de $6 \%$, nos níveis 9000 , 15000 e 18000 revoluções. O grau de refino foi avaliado através da determinação do grau Schopper-Riegler (SCAN-M3:65). Os resultados dos refinos individuais foram interpolados para $25^{\circ}$ SR através de análises de regressão. As folhas para os ensaios físico-mecânicos, foram formadas em aparelho formador tipo Köthen rapid, e acondicionadas em ambiente 
climatizado, nas condições de $50 \pm 2 \%$ de umidade relativa e temperatura de 23 $\pm 2^{\circ} \mathrm{C}$ (TAPPI T 402 om-93). As propriedades físico-mecânicas em graus de refino pré-estabelecidos foram as seguintes:

Peso Específico Aparente (TAPPI T 220 sp-96)

$$
\begin{aligned}
\mathrm{PEA}=\frac{\mathrm{G}}{\mathrm{E}} \quad \mathrm{PEA} & =\text { Peso Específico Aparente, } \mathrm{g} / \mathrm{cm}^{3} \\
\mathrm{G} & =\text { Gramatura, } \mathrm{g} / \mathrm{m}^{2} \\
\mathrm{E} & =\text { Espessura } \mathrm{um}
\end{aligned}
$$

Volume Específico Aparente (TAPPI T 220 sp-96)

$$
\begin{aligned}
& \text { VEA }=\frac{E}{G}=\frac{1}{P E A} \quad \text { VEA }=\text { Volume Específico Aparente, } \mathrm{cm}^{3} / \mathrm{g} \\
& \mathrm{G}=\text { Gramatura, } \mathrm{g} / \mathrm{m}^{2} \\
& \mathrm{E}=\text { Espessura, um }
\end{aligned}
$$

Índice de Rasgo (TAPPI T 414 om-98)

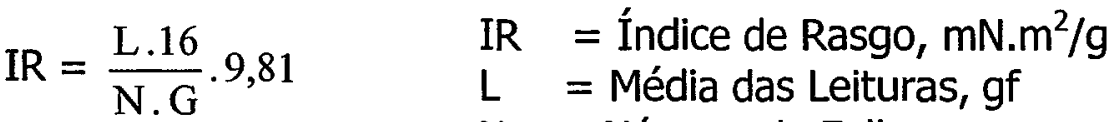

$$
\begin{aligned}
& \mathrm{N}=\text { Número de Folhas } \\
& \mathrm{G}=\text { Gramatura, } \mathrm{g} / \mathrm{m}^{2}
\end{aligned}
$$

Índice de Arrebentamento (TAPPI T 403 om-97)

$$
\begin{aligned}
\mathrm{IA}=\frac{\mathrm{P}}{\mathrm{G}} & \mathrm{IA}=\text { Índice de Arrebentamento, } \mathrm{kPa} \cdot \mathrm{m}^{2} / \mathrm{g} \\
\mathrm{P} & =\text { Pressão Média, } \mathrm{kPa} \\
\mathrm{G} & =\text { Gramatura, } \mathrm{a} / \mathrm{m}^{2}
\end{aligned}
$$

Índice de Tração

$$
\begin{aligned}
& \Pi=\frac{F M \cdot 1000}{L \cdot G} \quad \Pi=\text { Índice de Tração, N.m/g } \\
& \mathrm{FM}=\text { Força Máxima, } \mathrm{N} \\
& \mathrm{L}=\text { Largura da Tira, } \mathrm{mm} \\
& \mathrm{G}=\text { Gramatura, } \mathrm{g} / \mathrm{m}^{2}
\end{aligned}
$$


Índice de energia absorvida na tração

$$
\text { TTEA = } \frac{\text { TEA }}{\mathrm{G}} \quad \begin{aligned}
\text { TTEA } & =\text { Índice de energia absorvida na tração, } \mathrm{kJ} / \mathrm{kg} \\
\text { TEA } & =\text { Energia absorvida na tração, } \mathrm{J} / \mathrm{m}^{2} \\
\mathrm{G} & =\text { Gramatura, } \mathrm{g} / \mathrm{m}^{2}
\end{aligned}
$$

Índice de rigidez à tração

$$
\mathrm{IRIT}=\frac{\mathrm{RIT} \cdot 10^{3}}{\mathrm{G}}
$$

\subsubsection{Análise estatística}

Foi conduzido o teste $\mathrm{F}$ da análise da variância a nível de procedências para as características: densidade básica, comprimento, largura, diâmetro do lume e espessura das paredes das fibras, conteúdo de holocelulose, lignina e extrativos, rendimento em celulose, número kappa e teor de rejeitos. Para a densidade básica foi feita a análise a nível de progênies dentro de cada procedência. $O$ teste de compração de médias usado foi o Ismeans. Para as proprieades fsísicas e mecânicas das polpas foi ajustado um modelo de regresão em função de cada nível de refino, para interpolar todos os valores obtidos a $25^{\circ}$ Shopper-Riegler. 


\section{RESULTADOS E DISCUSÃO}

\subsection{Densidade básica}

A tabela 4 e a figura 8 mostram os valores das densidades básicas médias das procedências/progênies avaliadas. Observa-se que todos os valores encontram-se no intervalo de dados registrados na literatura para esta espécie. Por sua vez, estes valores podem serem considerados como interessantes devido a que estão dentro do intervalo recomendado de valores de densidade $\left(0,45\right.$ a $\left.0,65 \mathrm{~g} / \mathrm{cm}^{3}\right)$, para a produção de celulose. De acordo com vários autores, a utilização de madeiras com estes valores de densidade básica podem ser deslignificadas com relativa facilidade devido à boa penetração do licor, possuem uma baixa proporção de vasos grandes ou teor de parênquima, são de fácil picagem, resultam em baixo teor de rejeitos além de apresentar papéis com bons valores de resistências

O teste $\mathrm{F}$ da análise de variância (ao nível de $5 \%$ de probabilidade) detecta que existem diferenças significativas entre as procedências mostrando que as número 1 , 8 e 14 apresentam valores similares $(0,535 ; 0,521$ e 0,527 $\mathrm{g} / \mathrm{cm}^{3}$, respectivamente) e superiores às procedências $10,12,16$ e 21 (0,514; 0,$513 ; 0,513$ e $0,511 \mathrm{~g} / \mathrm{cm}^{3}$, respectivamente). Neste sentido, as melhores procedências, são da região sul do estado de Victória (Proced. 1), da região nordeste (Proced. 14) e da região do estreito de Bass (Proced. 8). 
Dos valores de densidade básica das progênies dentro de cada uma das procedências observa-se que ocorre uma maior variação dos valores dentro de cada das procedências do que entre as mesmas. Mesmo assim, o teste $F$ da analise da variância não detecta diferenças significativa ao nível de $5 \%$ de probabilidade entre as progênies dentro das procedências, exceto na número 14. Esta semelhança dentro dos valores de densidade básica a nível de progênie em cada uma das procedências não concorda com o reportado por vários autores, os quais mencionam que de modo geral, para várias características, é observada uma maior variação entre procedências do que entre progênies dentro de procedências (Orme, 1983).

Tabela 4. Valores de densidade básica em $\mathrm{g} / \mathrm{cm}^{3}$ das progênies que compõem cada uma das procedências/progênies de $E$. globulus

\begin{tabular}{|c|c|c|c|c|c|c|c|}
\hline & \multicolumn{7}{|c|}{ PROCEDÊNCIAS } \\
\hline & 1 & 8 & 10 & 12 & 14 & 16 & 21 \\
\hline & $0,543 a$ & $0,520 a$ & $0,505 a$ & $0,516 a$ & $0,523 b$ & $0,534 a$ & $0,544 a$ \\
\hline$\tilde{\omega}$ & $0,539 a$ & $0,531 a$ & $0,530 a$ & $0,516 a$ & $0,525 b$ & $0,522 a$ & $0,520 \mathrm{a}$ \\
\hline c & $0,522 \mathrm{a}$ & $0,513 a$ & $0,497 a$ & $0,497 a$ & $0,524 b$ & $0,514 a$ & $0,509 a$ \\
\hline 0 & & $0,527 a$ & $0,524 a$ & $0,530 a$ & $0,567 a$ & $0,494 a$ & $0,500 \mathrm{a}$ \\
\hline & & $0,542 a$ & & $0,506 a$ & $0,518 b$ & $0,494 a$ & $0,495 a$ \\
\hline Média & 0,535 & 0,527 & 0,514 & 0,513 & 0,531 & 0,511 & 0,513 \\
\hline
\end{tabular}

Nota: valores com igual letra não diferem significativamente pelo teste Ismeans ao nivel de $5 \%$ de probabilidade 


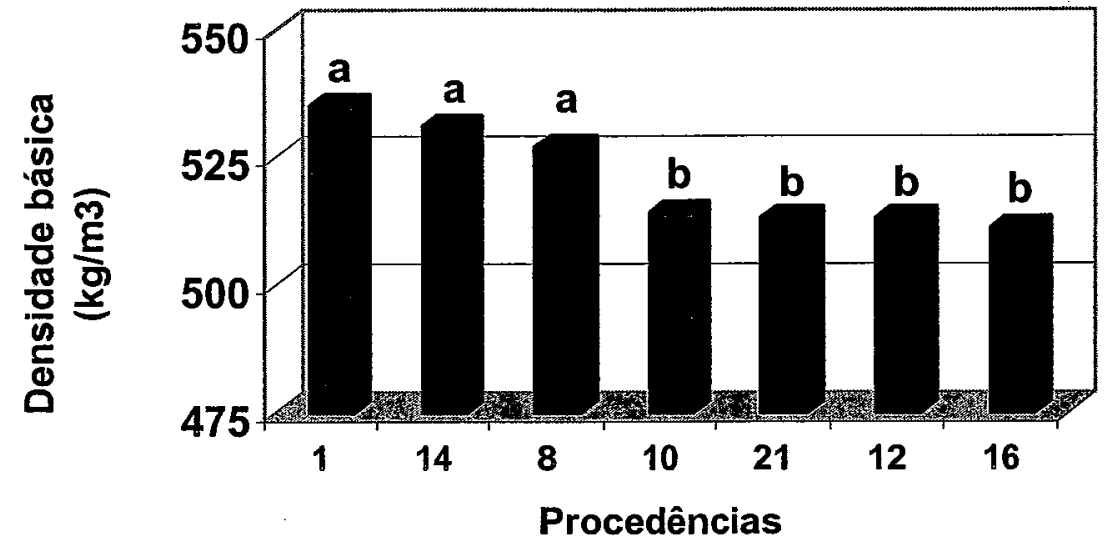

Figura 8 - Densidade básica média das procedências de $E$. globulus

Nota: valores com igual letra não diferem significativamente pelo teste Ismeans ao nível de $5 \%$ de probabilidade

\subsection{Dimensões das fibras}

Quanto às dimensões das fibras, a tabela 5 e a figura 9 mostram os valores de comprimento, largura, diâmetro do lume e espessura da parede das procedências avaliadas. De acordo com teste $F$ da análise da variância, observase que só existem diferenças significativas, ao nível de $5 \%$ de probabilidade, entre procedências, para a variável espessura da parede. Os valores de comprimento de todas as procedências são muitos similares entre sim além de serem muito próximos aos valores médios apresentados na literatura para esta espécie. Neste caso os valores variam de 0.88 a $0.94 \mathrm{~mm}$. 
Tabela 5. Comprimento, largura, diâmetro do lume espessura da parede das fibras das procedências de $E$. globulus

\begin{tabular}{cccccccc}
\hline & \multicolumn{7}{c}{ PROCEDÊNCIAS } \\
& 1 & 8 & 10 & 12 & 14 & 16 & 21 \\
\hline $\begin{array}{c}\text { Comprimento } \\
\quad(\mathrm{mm})\end{array}$ & 0,94 & 0,90 & 0,88 & 0,93 & 0,92 & 0,89 & 0,93 \\
$\quad \begin{array}{c}\text { Largura } \\
\quad(\mu \mathrm{m})\end{array}$ & 13,9 & 14,9 & 13,6 & 14,3 & 14,0 & 14,7 & 14,3 \\
$\begin{array}{c}\text { Diâmetro do lume } \\
\quad(\mu \mathrm{m})\end{array}$ & 7,9 & 9,2 & 8,3 & 9,0 & 8,3 & 9,6 & 9,1 \\
$\begin{array}{c}\text { Espessura da parede } \\
(\mu \mathrm{m})\end{array}$ & 3,0 & 2,8 & 2,7 & 2,6 & 2,8 & 2,5 & 2,6 \\
\hline
\end{tabular}



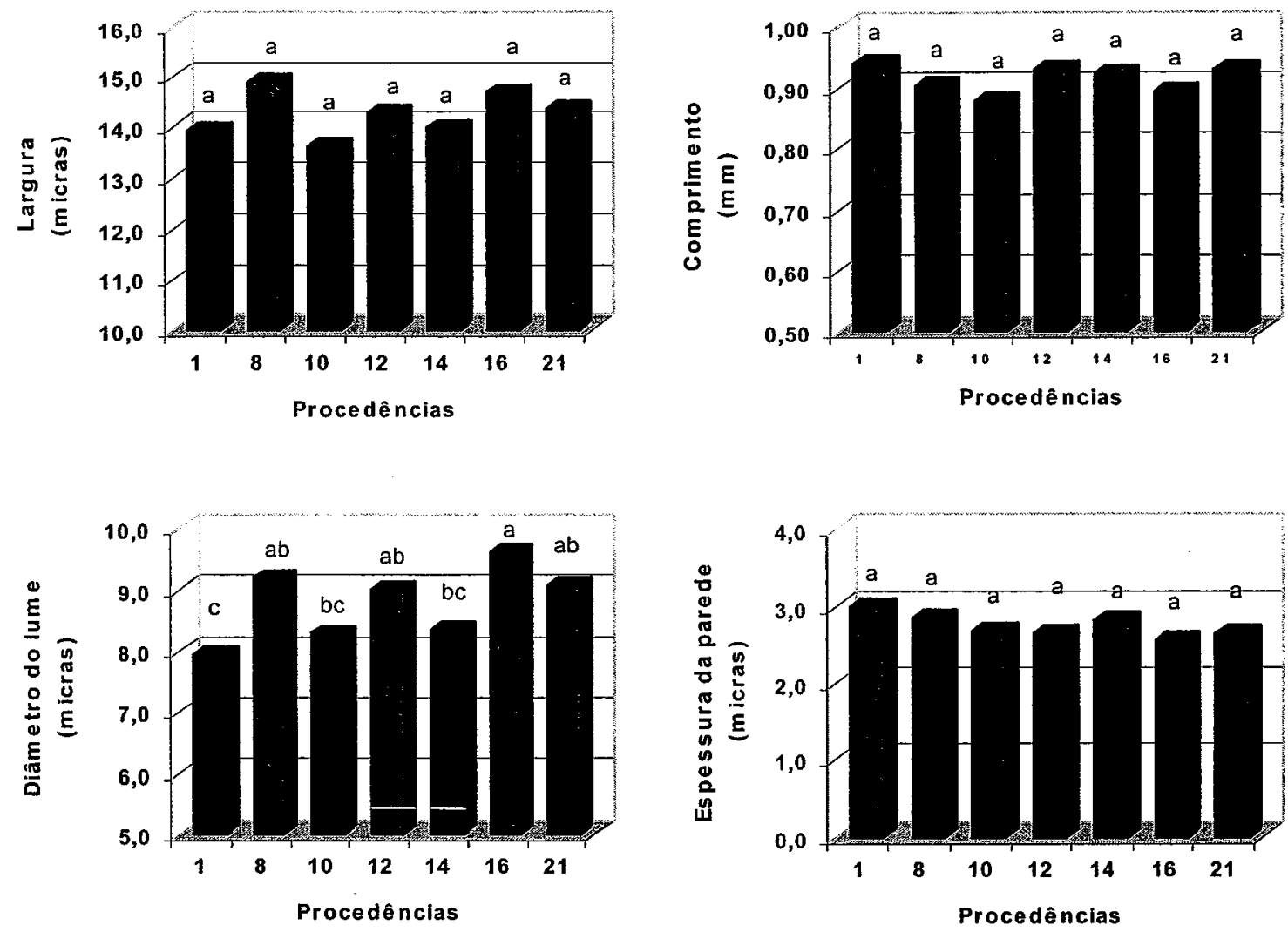

Figura 9 - Dimensões de fibras das procedências de E.globulus

Nota: valores com igual letra não diferem significativamente pelo teste Ismeans ao nível de $5 \%$ de probabilidade

Quanto aos valores de largura das fibras observa-se que todas as procedências apresentam valores muito próximos entre sim, variando de 13.6 a 14.9 micrômetros. Por sua vez, estes valores são algo inferiores aos reportados na literatura para esta espécie, devido talvez à menor idade das árvores utilizadas nesta avaliação. Analisando o comprimento e a largura das fibras não observa-se nenhuma relação entre as mesmas no sentido do que as procedências com fibras mais compridas não são as que apresentam as fibras de maior largura. Em relação ao diâmetro do lume das fibras, o teste de comparação de médias (Ismeans, ao nível de $5 \%$ probabilidade) mostra que os 
valores extremos correspondem às procedências 1 e 16, cujos valores médios são de 7.96 e 9.62 micrômetros, respectivamente. As demais procedências apresentam valores intermediários e estatisticamente iguais entre sim.

Finalmente, quanto à espessura da parede das fibras, pode-se observar que os valores seguem a tendência inversa do diâmetro do lume em função da forma de cálculo da mesma. De modo geral observa-se que as procedências com fibras de maior diâmetro do lume tem paredes mais finas. Se levamos em consideração que por um lado a espessura da parede surge da diferença da largura da fibra menos o diâmetro do lume e que os valores de largura das procedências são muito próximos entre sim, surge claro a relação existente entre as duas variáveis.

Nas tabelas 10, 1112 e 13 do ANEXO são apresentados os dados de dimensões das fibras de cada uma das progênies que compõem as procedências.

Analisando os valores de densidade básica junto com os valores das dimensões das fibras das diferentes procedências vemos que a densidade da madeira esta ligada a espessura da parede e/ou diâmetro do lume. Neste caso, como também é mencionado por vários autores, ocorre que as procedências cujas madeiras tem paredes de maior espessura tem mais substância madeira e menos espaços vazios por unidade de volume do que madeira com paredes mais finas. Isto implica na ocorrência de uma relação inversa entre o diâmetro do lume e a densidade, e uma relação direta entre esta última e a espessura da parede. Como pode ser notado, as procedências de madeiras mais densas $(1,8$ e 14) são as que apresentam paredes de fibras de maior espessura, enquanto que as demais procedências mostram uma tendência inversa. Também não se deve esquecer que além da espessura da parede, a densidade básica também 
está relacionada a outros fatores da madeira como a proporção e dimensão dos vasos, presença de extrativos e parênquima. Segundo Foelkel (1978), na opinião de alguns autores, somente quando se esteja considerando espécies similares, do ponto de vista anatômico (provavelmente seja o caso das procedências de E.globulus deste trabalho), é que a densidade básica pode ser explicada fundamentalmente pela espessura da parede.

$\mathrm{Na}$ tabela 6 e nas figuras 10 e 11 são apresentados os índices calculados a partir das diferentes dimensões das fibras das diferentes procedências. Analisando estas relações observa-se que o índice de Runkel e fração parede mostram uma estreita relação com a densidade da madeira, devido a que ambas dependem diretamente da espessura da parede. As procedências que apresentam os maiores valores destes índices são as número $1,14,10$ e 8 da mesma forma que a densidade, exceto pela procedência 10.0 coeficiente de flexibilidade, tem uma estreita relação inversa com a densidade devido a que é função direta do diâmetro do lume. Portanto, as procedências de maior densidade, vão ter menor diâmetro do lume e consequentemente menor coeficiente de flexibilidade. No caso do índice de enfeltramento, o mesmo depende da relação comprimento/largura de modo que tem muita pouca relação com a densidade da madeira. Todos este índices, em geral, são superiores aos reportados por Dias (1972), Queiroz (1972); Barrichelo \& Brito (1983); Gonzaga et al., (1984) e similares aos obtidos por Barrichelo \& Foelkel (1976). Considerando estes valores em relação à qualidade do papel que pode ser obtido com cada uma das procedências, pode-se dizer que todos os índices estão acima dos valores citados como os mais recomendáveis pela literatura. Neste sentido, menciona-se por vários autores que os valores ideais destes índices para produzir celulose seriam: índice de runkel abaixo de 1.5 ou 2, fração parede acima de $60 \%$ e peso específico aparente até $0.6 \mathrm{~g} / \mathrm{cm} 3$. (Foelkel, 
1978; Bamber, 1985; Dean, 1985, Paula \& Alves,1989). Os valores de cada um destes índices serão discutidos no capítulo referente às propriedades do papel.

Tabela 6. Índices calculados a partir dos valores das dimensões das fibras das procedências de E.globuluis

\section{PROCEDÊNCIAS}

\begin{tabular}{cccccccc} 
& 1 & 8 & 10 & 12 & 14 & 16 & 21 \\
\hline Índice de Runkel & 0,75 & 0,62 & 0,64 & 0,59 & 0,68 & 0,53 & 0,58 \\
Fração Parede & 43 & 38 & 39 & 37 & 40 & 35 & 37 \\
$\begin{array}{c}\text { Índice de } \\
\text { enfeltramento }\end{array}$ & 67 & 60 & 64 & 65 & 60 & 61 & 65 \\
$\begin{array}{c}\text { Coeficiente de } \\
\text { flexibilidade }\end{array}$ & 57 & 62 & 61 & 63 & 60 & 65 & 63 \\
\hline
\end{tabular}
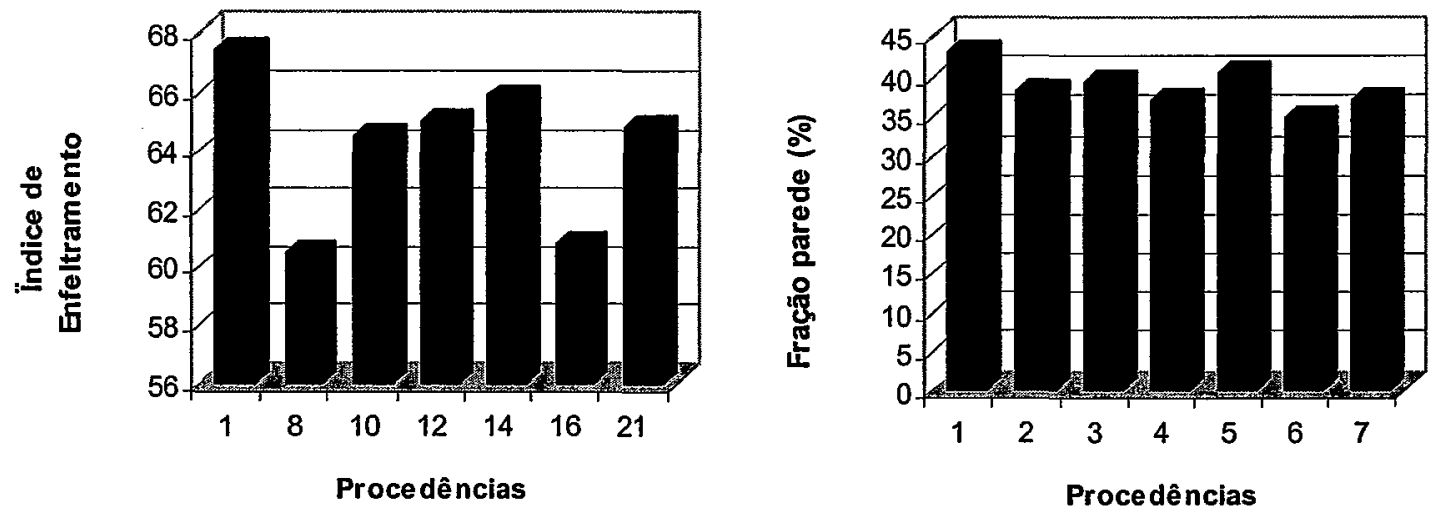

Figura 10 - Índice de enfeltramento e fração parade das procedências de E.globulus 

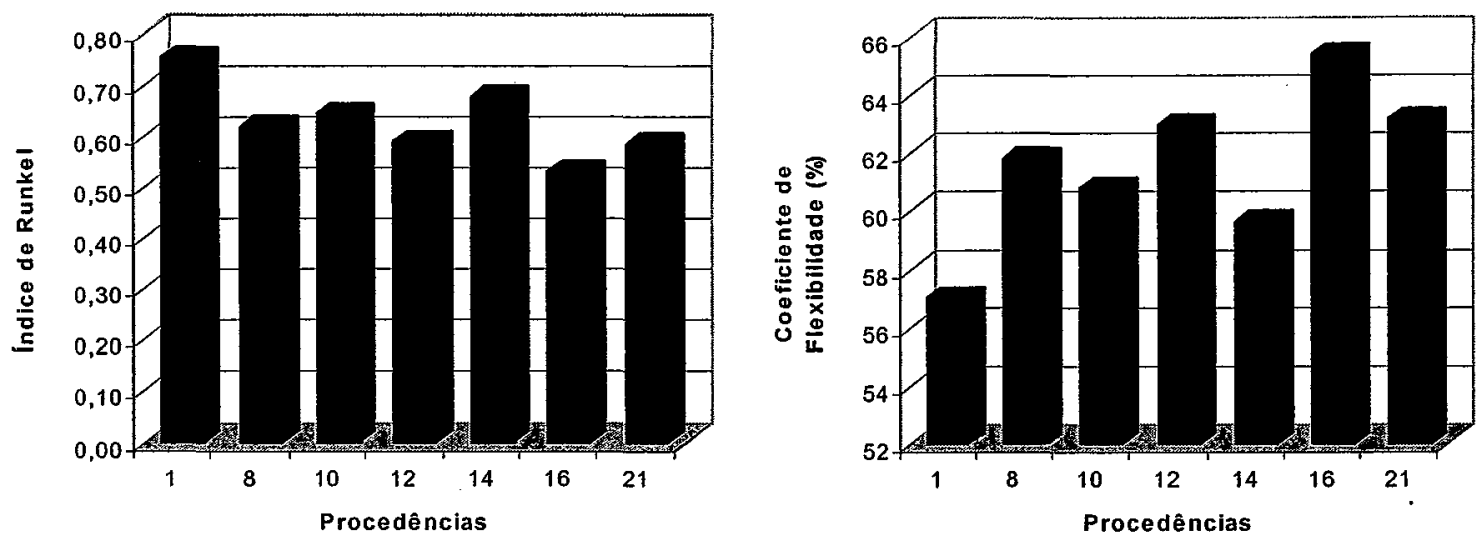

Figura 11 - Índice de runkel e coeficiente de flexibilidade das procedências de E.globulus

Nota: valores com igual letra não diferem significativamente pelo teste Ismeans ao nível de $5 \%$ de probabilidade

\subsection{Composição química}

Na tabela 7 e na figura 12 são apresentados os valores do teor lignina total (solúvel + insolúvel), holocelulose e extrativos totais para cada uma das procedências. De acordo com o teste $F$ da análise da variância não detectam-se diferenças significativas ao nível de $5 \%$ de probabilidade entre as procedências para nenhuma das características consideradas. Os teores de lignina total variam de 23,8 a $26 \%$, encontrando-se dentro do esperado nesta espécie a qual caracteriza-se por possuir um relativo baixo conteúdo de lignina quando comparado com outras espécies de Eucalyptus. Os teores de holocelulose determinados nas procedências variam de 69 a $72 \%$ e são um pouco mais baixo do que o reportado na literatura para esta espécie. 0 teor de extrativos totais das procedências variou de 3.8 a $4.8 \%$. 
Se analisamos a relação existente entre os teores dos compostos químicos anteriormente referidos para todas as procedências vemos que existe uma clara relação negativa entre o teor de holocelulose e o teor de lignina $\left(r^{2}=\right.$ $-0.87^{* *}$ ), indicando que aquelas procedências com maiores teores de holocelulose apresentam, de modo geral, os menores teores de lignina. A relação entre o teor de lignina total e de extrativos totais foi praticamente nula $\left(r^{2}=-0.09 n s\right)$, enquanto que a relação entre o teor de holocelulose e de extrativos teve um comportamento intermédio $\left(r^{2}=-0.56^{* *}\right)$. Tendências similares foram estabelecidas por vários autores estudando a composição química da madeira de E.grandis (Barrichelo \& Brito, 1977; Vital et al., 1986; Dos Santos, 2000).

Quanto à relação da densidade básica com os teores de lignina total, holocelulose e extrativos totais, os valores de correlação calculados indicam que o grau de associação entre estes parâmetros é nulo $\left(r^{2}=-0.16 n s\right.$, $r^{2}=0.14 n$ s e $r^{2}=-0.004 n s$, respectivamente). Estes resultados concordam com os resultados obtidos por Shimoyama, 1990; Dos Santos, 2000, a pesar de que na literatura são reportados resultados que indicam que a relação entre estes parâmetros pode-se apresentar de forma muito diversa (Barrrichelo \& Brito, 1977, Vital et al. 1986; Vasconcelos Dias \& Cláudio da Silva Júnior, 1985; Wehr, 1991). 
Tabela 7. Teores de lignina total, holocelulose e extrativos totais das procedências de E.globulus

\begin{tabular}{cccccccc}
\hline & \multicolumn{7}{c}{ PROCEDÊNCIAS } \\
& 1 & 8 & 10 & 12 & 14 & 16 & 21 \\
\hline $\begin{array}{c}\text { Lignina total } \\
\text { (\%) }\end{array}$ & 24,8 & 23,8 & 24,5 & 24,9 & 24,6 & 26,0 & 25,3 \\
$\begin{array}{c}\text { Holocelulose } \\
\text { (\%) }\end{array}$ & 70,6 & 71,4 & 71,7 & 70,4 & 70,7 & 69,2 & 70,6 \\
$\begin{array}{c}\text { Extrativos totais } \\
\text { (\%) }\end{array}$ & 4,6 & 4,8 & 3,8 & 4,7 & 4,6 & 4,8 & 4,2 \\
\hline
\end{tabular}
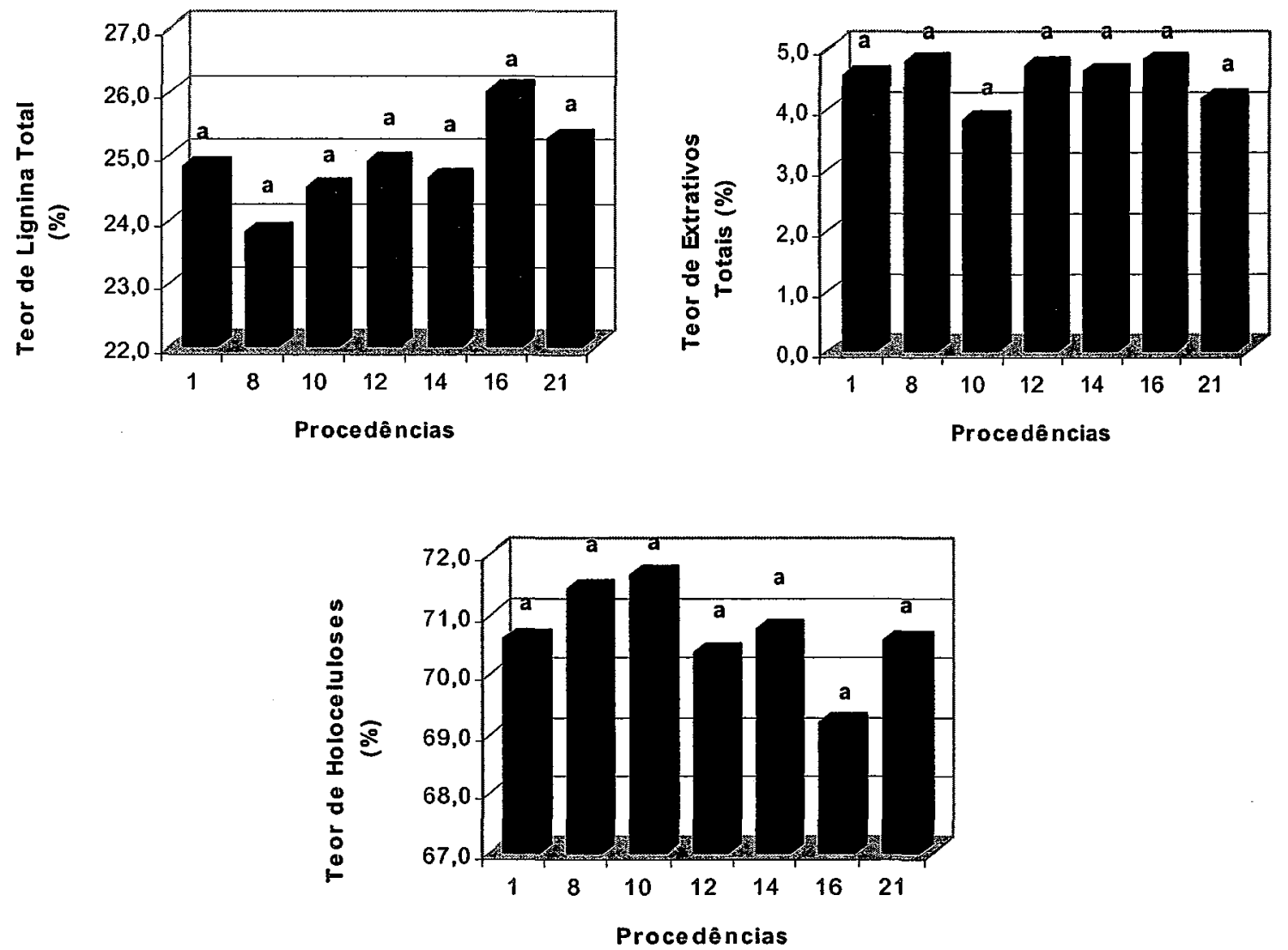

Figura 12 - Composição química da madeira das procedências de E.globulus. 
Nas tabelas 14, 15 e 16 do ANEXO são apresentados os dados da composição química de cada uma das progênies que compõem as procedências.

\subsection{Cozimento kraft}

Na tabela 8 e figura 13 são apresentados os valores de rendimento depurado, número kappa, relação rendimento kappa e o teor de rejeitos base madeira para todas as procedências avaliadas. Apesar do teste $\mathrm{F}$ da análise da variância não mostrar a existência de diferenças significativas (ao nível de $5 \%$ de probabilidade) entre procedências para o rendimento depurado, número kappa o teor de rejeitos, podem-se comentar algumas tendências observadas. Considerando os parâmetros da composição química da madeira, nota-se que as procedências que tem os maiores valores de rendimento depurado são as que possuem o menores teores de lignina na sua madeira. Isto estaria provocando uma deslignifcação mais fácil dessas procedências do que aquelas com altos teores de lignina. As procedências 16 e 21, são as que apresentam os menores valores de rendimento depurado ao mesmo tempo que são as que tem os maiores teores de lignina. Por sua vez as procedências 1, 10 e 12, que são as de melhores rendimentos, possuem baixos teores de lignina. Dos resultados obtidos, não se observa relação entre o teor de lignina e o número kappa da mesma forma que entre o rendimento depurado e o número kappa. Por outra lado, observa-se de modo geral considerando os valores médios das procedências, uma relação positiva entre os valores de rendimento depurado e o teor de holocelulose e uma relação negativa entre os valores de rendimento depurado e os teores de lignina. Resultados similares com E.grandis foram obtidos por Barrichelo \& Brito, 1977; Amidon, 1981; Barrichelo et al., 1983; Dos Santos, 2000. Devido a que os valores de rendimento depurado não mostram praticamente nenhuma relação com os valores de número kappa das 
procedências, calculou-se a relação entre estes dois parâmetros de forma de poder comprar as procedências com diferentes números kappa . Esta relação indica que as procedências $8,10,12$ e 21 são as que mostram o melhor grau de deslignificação devido aos baixos teores de lignina além de possuírem os menores valores de densidade básica o que eventualmente facilitou a penetração do licor e posterior remoção da lignina. Esta diferente facilidade de impregnação e da difusão do licor pode estar influenciada pelas eventuais diferenças na porosidade da madeira das diferentes procedências associada aos diferentes valores do diâmetro do lume e espessura da parede das fibras o qual esta intimamente ligado à densidade básica.

Tabela 8. Valores de rendimento depurado, número kappa, teor de rejeitos e relação rendimento/kappa das procedências de E.globulus

\begin{tabular}{|c|c|c|c|c|c|c|c|}
\hline & \multicolumn{7}{|c|}{ PROCEDÊNCIAS } \\
\hline & 1 & 8 & 10 & 12 & 14 & 16 & 21 \\
\hline $\begin{array}{l}\text { Rendimento } \\
\text { depurado } \\
(\%)\end{array}$ & 51 & 50 & 51 & 51 & 50 & 48 & 49 \\
\hline Número kappa & 20 & 18 & 18 & 19 & 21 & 20 & 17 \\
\hline $\begin{array}{c}\text { Teor de rejeitos } \\
(\%)\end{array}$ & 0,6 & 0,4 & 0,4 & 0,4 & 0,7 & 0,5 & 0,3 \\
\hline $\begin{array}{c}\text { Relação } \\
\text { Rend/kappa }\end{array}$ & 2,6 & 2,7 & 2,8 & 2,7 & 2,4 & 2,4 & 2,9 \\
\hline
\end{tabular}



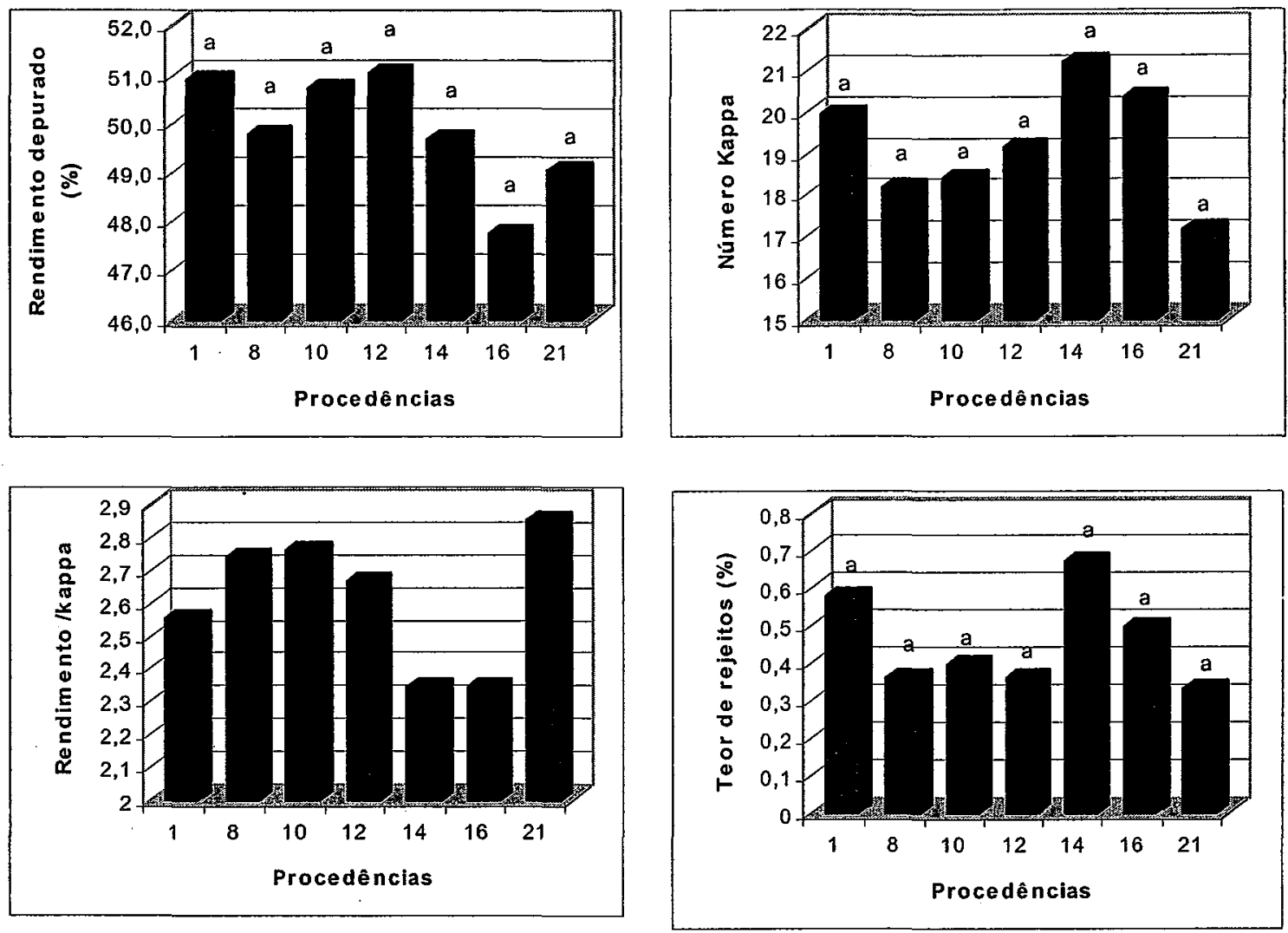

Figura 13 - Resultados do cozimento Kraft das procedências de E.globulus.

Nota: valores com igual letra não diferem significativamente pelo teste Ismeans ao nível de $5 \%$ de probabilidade

Dos valores de correlação estimados observa-se que não existe relação entre os valores de densidade básica com nenhum dos parâmetros de deslignificação nem da composição química da madeira. Os valores obtidos são apresentados na tabela 9 . 
Tabela 9. Valores de correlação da densidade básica com parâmetros da deslignificação e composição química

\begin{tabular}{lcccccc}
\hline & $\begin{array}{c}\text { Rendimento } \\
\text { depurado }\end{array}$ & $\begin{array}{c}\text { Teor de } \\
\text { rejeitos }\end{array}$ & $\begin{array}{c}\text { Número } \\
\text { kappa }\end{array}$ & $\begin{array}{c}\text { Teor de } \\
\text { holocelulose }\end{array}$ & $\begin{array}{c}\text { Teor de } \\
\text { lignina } \\
\text { total }\end{array}$ & $\begin{array}{c}\text { Teor de } \\
\text { extrativos } \\
\text { totais }\end{array}$ \\
\hline $\begin{array}{l}\text { Densidade } \\
\text { básica }\end{array}$ & $0,25 \mathrm{~ns}$ & $0,14 \mathrm{~ns}$ & $0,33 \mathrm{~ns}$ & $0,13 \mathrm{~ns}$ & $0,16 \mathrm{~ns}$ & $-0.04 \mathrm{~ns}$ \\
\hline
\end{tabular}

Nota: ns - não significativo

Através dos resultados obtidos pode-se dizer que para as condições desta avaliação, a densidade básica não é um bom indicador do comportamento das procedências em relação aos resultados da deslignificação e a composição química das mesmas. Resultados similares estudando várias espécies de Eucalyptus foram obtidos por Foelkel, 1974; Barrichelo et al., 1983; Turner, Balodis \& Dean, 1983; Vasconcelos Dias \& Cláudio da Silva Júnior, 1985; Goyal, 1999; Dos Santos, 2000. Por outro lado, concordando com vários resultados apresentados na literatura, observa-se que os melhores preditores da qualidade da madeira quanto as características da polpação são os teores de holocelulose e lignina.

Nas tabelas 17, 18, 19 e 20 do ANEXO são apresentados os dados da polpação kraft de cada uma das progênies que compõem as procedências.

\subsection{Propriedades físicas e mecânicas das polpas}

Na figura 14 e nas tabelas 21, 22, 23 e 24 do ANEXO são 
volume específico aparente e o Índice de tração em função do número de revoluções.
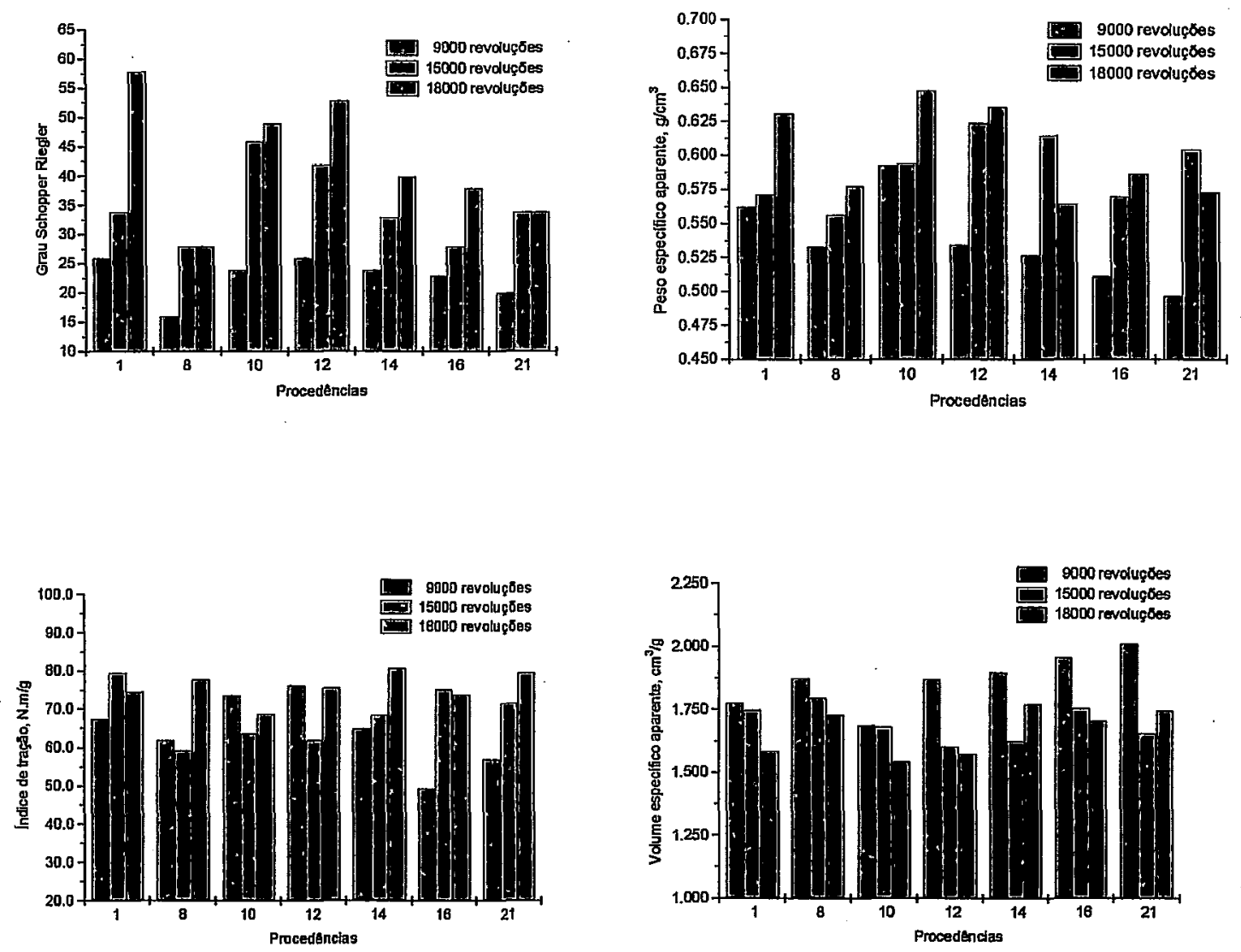

Figura 14 - Resultados de peso específico aparente, volume específico aparente, grau Shopper-Riegler, índice de tração de polpas das procedências de $E$. globulus

A análise do grau Schopper-Riegler permite verificar a sua elevação com o aumento do número de revoluções (tempo de refino ou consumo de energia de refino), como era de se esperar de acordo com a literatura (Foelkel, 1974; Bueno Zárate \& Trujillo Gironda, Reinoso, 1983; Barrichelo \& Brito, 1983; Gonzaga, 1984; Ludeña Lara \& Bueno Zárate, 1989; Sansígolo \& Curvelo; 1995 e Ferreira \& Figueredo, 2001). A análise comparativa dos graus Schopper 
e Ferreira \& Figueredo, 2001). A análise comparativa dos graus Schopper Riegler mostra comportamentos diferentes no refino, ou seja, algumas procedências refinaram mais rápido que outras. As procedências 1,10 e 12 refinaram mais rapidamente que as demais. A procedência 1, apesar de ter paredes relativamente espessas, apresentou um alto grau de refino, principalmente para o maior tempo de moagem, o qual pode ser explicado pela menor degradação dos polissacarídeos durante a polpação, representado pelo alto rendimento depurado. De acordo com Astals (1995), . o alto teor de hemiceluloses proporciona maior hidratação e plastificação das fibras o que facilitaria o refino. As procedências 10 e 12, também, refinaram rapidamente, devido aos valores inferiores de densidade básica da madeira, valores superiores de rendimento depurado (menor degradação de hemicelulose) e menores número Kappa. A procedência 8 foi a mais difícil de ser refinada, podendo ser atribuído as fibras mais espessas e rendimento da polpação. As procedências 14, 16, 21 tiveram facilidade de refino intermediária.

Os valores de peso específico aparente se elevaram com a elevação do tempo de refino, conforme citado na literatura para várias espécies de Eucalyptus. Deste modo, o refino aumenta o grau de ligação das fibras fazendo com que a folha se torne cada vez mais compacta por unidade de volume e, conseqüentemente, com maior densidade (Foelkel, 1974; Barrichelo \& Foelkel, 1976; Bugajer, 1979; Barrichelo \& Brito, 1983; Reinoso, 1983; Gonzaga, 1984; Texeira \& Soares, 1992; Sansígolo \& Curvelo, 1995; Ferreira \& Figueredo, 2001; Kibblewhite, 2001). De um modo geral, madeira de alta densidade básica produz polpa com maior volume específico aparente (menos densa); polpa com menor teor de hemiceluloses tem menor hidratação e plastificação das fibras e contribue para elevação do volume específico e polpa com maior teor de lignina residual aumenta a rigidez das fibras e conseqüentemente maior volume 
específico. As polpas das procedências 14, 16 e 21 apresentaram valores inferiores de peso específico aparente (polpas mais volumosas). Estas procedências apresentaram os menores rendimentos da polpação e número Kappa mais elevado para as de número 14 e 16.

Os índices de tração das polpas das procedências estão bastante próximos aos reportados por vários autores, para condições similares às deste experimento (Queiroz, 1972; Foelkel, 1974; Barrichelo \& Foelkel, 1976; Barrichelo \& Brito, 1976; Barrichelo \& Brito, 1983; Gonzaga, 1984; Valente, et al. 1992; Van Wyk \& Gerischer, 1994). Nota-se que a tendência das procedências (apesar da existência de valores discordantes) foi de um aumento no valor do índice de tração conforme aumenta o tempo de refino. Na condição de 9000 revoluções, os valores mais altos foram obtidos pelas procedências 10, 12 e $14(74,76$ e $75 \mathrm{~N} . \mathrm{m} / \mathrm{g}$, respectivamente) e os menores pelas procedências 16 e 21 (49 e $57 \mathrm{~N} . \mathrm{m} / \mathrm{g}$, respectivamente). Na condição de 18000 revoluções todos os valores foram muito próximos e na faixa de $70-80 \mathrm{~N} . \mathrm{m} / \mathrm{g}$. De modo geral, as procedências $1,10,12$, e 14 mostraram os valores mais altos de tração explicados pelos altos valores do índice de enfeltramento (I.E.), além dos baixos valores do coeficiente de flexibilidade (C.F.). As fibras com maior índice de enfeltramento tem maior facilidade de cruzamentos e por tanto mais áreas de ligações disponíveis. Por outro lado, os baixos valores de coeficiente de flexibilidade implica uma alta relação entre o diâmetro do lume e largura da fibra, o que indica um maior achatamento das fibras na formação da folha. Estes resultados concordam com os obtidos por Dadswell \& Watson, (1961); Tamolang \& Wangaard, (1961); Wangaard et al., (1966); Foelkel \& Barrichelo, (1975); Repetti, (1990); Paula \& Alves, (1980) apesar de que em alguns destes trabalhos menciona-se uma relação positiva entre a resistência à tração e a fração parede e inversa com o índice de Runkel, aspecto que não foi observado 

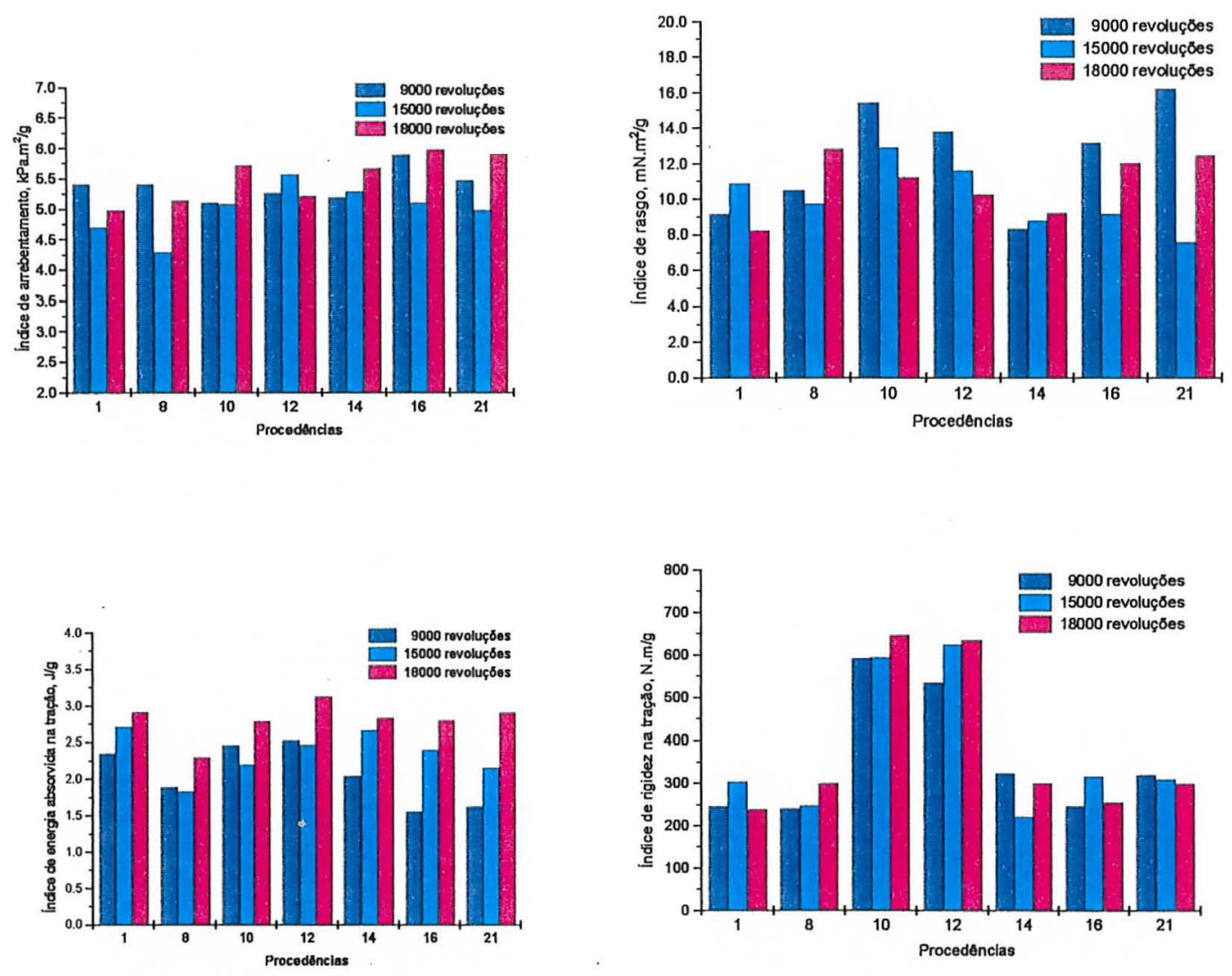

Figura 15 - Resultados do índice de arrebentamento, rasgo, energia absorvida na tração e rigidez na tração de polpas das procedências de E.globulus

Na Figura 15 e nas tabelas 25, 26, 27 e 28 do ANEXO são apresentados os valores de índice de arrebentamento, índice de rasgo, índice de energia absorvida na tração e índice de rigidez na tração.

Quanto aos valores do índice de arrebentamento obtidos nas procedências pode-se dizer que os mesmos são um pouco inferiores aos obtidos por Queiroz (1972), Foelkel (1974), Barrichelo \& Foelkel (1976), Barrichelo \& Brito (1976) , Barrichelo \& Brito (1983), Gonzaga et al. (1984a,b) , Van Wyk \& 
Quanto aos valores do índice de arrebentamento obtidos nas procedências pode-se dizer que os mesmos são um pouco inferiores aos obtidos por Queiroz (1972), Foelkel (1974), Barrichelo \& Foelkel (1976), Barrichelo \& Brito (1976) , Barrichelo \& Brito (1983), Gonzaga et al. (1984a,b) , Van Wyk \& Gerischer (1994) e superiores aos reportados por Bustamante \& Santos (1981), Reinoso (1983), Ludeña Lara \& Bueno Zárate (1989), Zárate \& Gironda (1980,1981), Tejada \& Gonzáles (1989); Sansígolo \& da Silva Curvelo, (1995). O aumento do número de revoluções não mostrou a tendência esperada quanto ao aumento do índice de arrebentamento, na maioria das procedências. Também não se observa nenhuma relação destes valores com os valores do índice de tração como é mencionado na literatura. No entanto, concordando com vários trabalhos, estes valores mostraram a existência de uma relação positiva com os valores de coeficiente de flexiblidade e com o diâmetro do lume das fibras pelas mesmas razões que foram mencionadas para a resistência à tração (Watson \& Dadswell, 1961; Tamolang \& Wangaard, 1961; Wangaard et al., 1966; Foelkel \& Barrichelo, 1975). Nota-se que todas as procedências apresentaram valores muito próximos variando de 5,1 a $5,9 \mathrm{kPa} . \mathrm{m}^{2} / \mathrm{g}$ para 9000 revoluções (procedências 10 e 16, respectivamente) e de 5,2 a $6,0 \mathrm{kPa} \cdot \mathrm{m}^{2} / \mathrm{g}$ para 18000 revoluções (procedências 12 e 16, respectivamente.

Em relação aos valores do índice de rasgo pode-se afirmar que os mesmos estão próximos aos citados na literatura para esta espécie (Queiroz, 1972; Foelkel, 1974; Barrichelo \& Foelkel, 1976; Barrichelo \& Brito, 1976; Barrichelo \& Brito, 1983; Gonzaga et al., 1984a,b; Valente, et al. 1992; Van Wyk \& Gerischer, 1994; Willimas et al., 1995). Com as procedências 1, 10 e 12 ocorre, como era de esperar, uma diminuição na resistência ao rasgo com o aumento do tempo de refino enquanto que para as procedências 16 e 21 esse comportamento só foi observado ao passar de 9000 para 18000 revoluções. As 
demais procedências mostraram um comportamento atípico. A tendência dos valores de resistência ao rasgo das procedências mostrou que os mesmos estariam relacionados positivamente com o índice de enfeltramento. Isto está de acordo com o obtido por Watson \& Dadswell (1961), Tamolang \& Wangaard (1961), Wangaard et al. (1966), Foelkel \& Barrichelo (1975) e Paula \& Alves (1989). Segundo estes autores existem vários parâmetros que também tem relação positiva com a resistência, mas tal fato não foi observado neste caso. Para os três níveis de revoluções, em media, os valores mais altos de resistência ao rasgo foi obtido das procedências $10,12,16$ e 21 . Para 9000 revoluções os valores de resistências foram $15,5,13,8,13,2$ e $16,2 \mathrm{mN} \cdot \mathrm{m}^{2} / \mathrm{g}$, respectivamente e para 18000 revoluções $11,2,10,3,12,1,12,5 \mathrm{mN} \cdot \mathrm{m}^{2} / \mathrm{g}$, respectivamente. Estas procedências apresentaram os menores valores de densidade básica o que estaria indicando uma relação negativa entre a resistência ao rasgo e o diâmetro do lume das fibras como é mencionado pelos autores anteriormente referidos.

A tendência dos três parâmetros analisados (rasgo, tração e arrebentamento) mostra do mesmo modo que para o grau Shopper-Riegler e peso específico, cada uma das procedências tem uma resposta diferente dependendo do tempo de refino. Portanto, o melhor resultado de cada uma das procedências avaliadas está em função do tempo de refino usado.

Dos resultados do índice de energia absorvida na tração pode-se observar que os mesmos, de modo geral, aumentam com a elevação do tempo de refino. Esta resposta foi mais marcada nas procedências 16 e 21, de igual modo que para o peso específico e o índice de tração. Os valores obtidos são inferiores aos reportados por Palmer (1982) o qual avaliou árvores com 10 e 33 anos de idade obtendo valores próximos a 3,5 J/g. No presente experimento, para 9000 revoluções os valores mais altos foram obtidos pelas procedências 1,10 e 12 $(2,35,2,47$ e $2,54 \mathrm{~J} / \mathrm{g}$, respectivamente) e para 18000 revoluções os mais altos 
foram das procedências 1 , 12 e 21 (2,92, 3,13 e 2,91 J/g, respectivamente). A energia absorvida na tração é uma medida da habilidade do papel absorver energia e indica a durabilidade do papel quando submetido a esforços ou tensões repetitivas. É definida pelo trabalho de ruptura (área sob a curva resistência à tração/alongamento) por unidade de área (comprimento x largura da tira de papel), conforme norma TAPPI T 494 om-96.

Da análise dos resultados do índice de rigidez na tração, destacam-se as procedências 10 e 12, por apresentarem os maiores valores nos três níveis de refino (593, 595 e 648 N.m/g e 535, 625 e $636 \mathrm{~N} . \mathrm{m} / \mathrm{g}$, respectivamente). A rigidez à tração é a melhor indicação de resposta mecânica da folha para converter força. É calculada pelo produto do módulo de elasticidade (região onde a resistência à tração é proporcional ao alongamento) $x$ espessura do papel, conforme norma TAPPI T 494 om-96.

Nas tabelas $21,22,23,24,25,26,27$ e 28 do ANEXO são apresentados os dados das propriedades físicas e mecânicas das polpaas de cada uma das progênies que compõem as procedências. 


\section{CONCLUSÕES}

Os valores de densidade básica de todas as procedências estão dentro dos valores considerados como mais recomendáveis para a produção de celulose.

As procedências com os valores mais altos de densidade básica foram da região sul do estado de Victória (Procedência1), da região nordeste (Procedência 14) e da região do estreito de Bass (Procedência 8). Os valores obtidos foram: $0,535,0,531$ e $0,527 \mathrm{~g} / \mathrm{cm}^{3}$, respectivamente. Estes valores estão relacionados positivamente com os valores de espessura da parede negativamente com o diâmetro do lume mostrados por essas procedências.

De modo geral, a variação observada nos valores de densidade básica a nível de progênies dentro das procedências foi tão alta quanto entre procedências

A densidade básica não mostrou relação com os componentes químicos da madeira (lignina, holocelulose e extrativos) nem com os parâmetros da deslignificação (rendimento depurado, teor de rejeitos e número kappa). 
Não se observou nenhuma relação entre o comprimento e a largura das fibras. As procedências com fibras de maior diâmetro do lume apresentaram a menor espessura da parede das fibras.

Dos índices calculados a partir das dimensões das fibras pode-se afirmar que todas as procedências são consideradas de boa qualidade para produzir papel.

Os valores de lignina total são relativamente próximos para todas as procedências e relativamente baixos, de acordo ao esperado para esta espécie. Os teores variaram de 23,8 a $26 \%$. Os teores de holoceluloses, também foram muito próximos e um pouco inferiores aos citados na literatura para esta espécie. Os teores obtidos variaram de 69 a $72 \%$. Os teores de extrativos totais variaram de 3,8 a $4,8 \%$.

O teor de lignina não mostrou nenhuma relação com o teor de extrativos, enquanto que o teor de holocelulose está associado negativamente com o teor de extrativos.

Os valores mais altos de rendimento depurado correspondem às procedências do sul de Victoria (1), Nordeste de Tasmânia (10) e do estreito de Bass (12). As três procedências apresentaram em média $51 \%$ de rendimento depurado.

$O$ teor de lignina total da madeira. pode ser considerado como um bom preditor do comportamento da madeira quanto ao processo de deslignificação kraft. O teor de extrativos não teve relação com o rendimento depurado. 
A melhor relação rendimento depurado/número kappa foi obtida pelas procedências 8, 10, 12 e 21, indicando que a lignina foi removida mais facilmente do que nas demais procedências e que as mesmas podem serem consideradas como as mais fáceis de branquear.

As procedências 1, 10 e 12 mostraram serem as mais fáceis de refinar e as que apresentaram os maiores valores de peso específico aparente das polpas para um valor de $25^{\circ} \mathrm{SR}\left(0,563,0,593\right.$ e $0,535 \mathrm{~g} / \mathrm{cm}^{3}$, respectivamente).

Os valores mais altos de resistência à tração foram obtidos nas procedências 1 , 10, 12 e 14 para um valor de $25^{\circ}$ SR (67,6; 73,8; 76,4 e 65,1 N.m/g., respectivamente).

Os valores do índice de arrebentamento foram muitos próximos para todas as procedências nas três condições de refino variando de 5,1 a 6,0 $\mathrm{kPa} \cdot \mathrm{m}^{2} / \mathrm{g}$.

Os valores mais altos de resistência ao rasgo foram obtidos pelas procedências 10,12 , 16 e 21 para um valor de $25^{\circ} \mathrm{SR}(15,5 ; 13,8 ; 13,2$ e 16,2 $\mathrm{mN} . \mathrm{m}^{2} / \mathrm{g}$, respectivamente).

Tanto para as propriedades físicas quanto para as propriedades mecânicas das polpas observou-se que o comportamento das procedências foi diferente dependendo do tempo de refino, sugerindo a existência de uma possível interação entre os dois fatores (procedências vs. tempo de refino), apesar de não ter sido analisada. 
Baseado nos resultados obtidos pode-se concluir que, do ponto de vista tecnológico, as procedências mais recomendáveis em termos de rendimento depurado e número Kappa são a 1 (sul de Vitória), 10 (ilha Cape Barren do estreito de Bass) and 12 (nordeste da Tasmânia). As procedências 10 e 12 foram as que mostraram a melhor performance em termos de facilidade de refino e resistências da polpa. 
ANEXOS 
Tabela 10. Valores de comprimento das fibras $(\mathrm{mm})$ das progênies que compõem cada uma das procedências de E.globulus

\begin{tabular}{|c|c|c|c|c|c|c|c|}
\hline & \multicolumn{7}{|c|}{ PROCEDÊNCIAS } \\
\hline & 1 & 8 & 10 & 12 & 14 & 16 & 21 \\
\hline$n$ & 0,88 & 0,90 & 0,94 & 0,99 & 0,93 & 0,95 & 1,02 \\
\hline$\frac{0}{c}$ & 0,95 & 0,86 & 0,86 & 1,01 & 0,97 & 0,84 & 0,95 \\
\hline 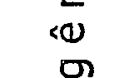 & 0,98 & 0,92 & 0,87 & 0,87 & 0,93 & 0,91 & 0,86 \\
\hline 0 & & 0,87 & 0,84 & 0,86 & 0,98 & 0,87 & 0,91 \\
\hline$a$ & & 0,97 & & 0,90 & 0,80 & 0,89 & 0,91 \\
\hline Média & 0,94 & 0,90 & 0,88 & 0,93 & 0,92 & 0,89 & 0,93 \\
\hline
\end{tabular}

Tabela 11. Valores de largura das fibras $(\mu \mathrm{m})$ das progênies que compõem cada uma das procedências de E.globulus

\begin{tabular}{|c|c|c|c|c|c|c|c|}
\hline & \multicolumn{7}{|c|}{ PROCEDÊNCIAS } \\
\hline & 1 & 8 & 10 & 12 & 14 & 16 & 21 \\
\hline n & 14,5 & 14,9 & 13,4 & 14,1 & 14,6 & 15,8 & 13,9 \\
\hline$\frac{d}{c}$ & 13,0 & 14,2 & 13,9 & 15,0 & 14,4 & 13,9 & 13,8 \\
\hline < & 14,3 & 16,0 & 13,6 & 14,7 & 13,5 & 15,3 & 14,1 \\
\hline 2 & & 13,9 & 13,7 & 13,5 & 14,1 & 14,4 & 14,7 \\
\hline 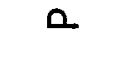 & & 15,6 & & 14,1 & 13,4 & 14,1 & 15,1 \\
\hline Média & 13,9 & 14,9 & 13,6 & 14,3 & 14,0 & 14,7 & 14,3 \\
\hline
\end{tabular}


Tabela 12. Valores de diâmetro do lume das fibras $(\mu \mathrm{m})$ das progênies que compõem cada uma das procedências de E.globulus

\begin{tabular}{|c|c|c|c|c|c|c|c|}
\hline & \multicolumn{7}{|c|}{ PROCEDÊNCIAS } \\
\hline & 1 & 8 & 10 & 12 & 14 & 16 & 21 \\
\hline n & 8,8 & 8,6 & 7,7 & 8,9 & 9,1 & 10,7 & 8,5 \\
\hline$\frac{\pi}{c}$ & 7,1 & 8,7 & 8,1 & 9,3 & 8,7 & 9,2 & 8,8 \\
\hline 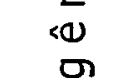 & 8,0 & 10,9 & 8,5 & 9,2 & 7,7 & 10,0 & 9,0 \\
\hline 0 & & 8,2 & 8,9 & 8,4 & 7,5 & 9,0 & 9,7 \\
\hline$\Omega$ & & 9,7 & & 9,2 & 8,8 & 9,2 & 9,4 \\
\hline Média & 7,9 & 9,2 & 8,3 & 9,0 & 8,3 & 9,6 & 9,1 \\
\hline
\end{tabular}

Tabela 13. Valores de espessura da parede das fibras $(\mu \mathrm{m})$ das progênies que compõem cada uma das procedências de E.globulus

\begin{tabular}{|c|c|c|c|c|c|c|c|}
\hline & \multicolumn{7}{|c|}{ PROCEDÊNCIAS } \\
\hline & 1 & 8 & 10 & 12 & 14 & 16 & 21 \\
\hline os & 2,9 & 3,1 & 2,8 & 2,6 & 2,7 & 2,5 & 2,7 \\
\hline$\frac{1}{c}$ & 3,0 & 2,7 & 2,9 & 2,9 & 2,9 & 2,4 & 2,5 \\
\hline 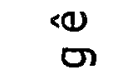 & 3,1 & 2,6 & 2,6 & 2,8 & 2,9 & 2,6 & 2,6 \\
\hline 은 & & 2,8 & 2,4 & 2,5 & 3,3 & 2,7 & 2,5 \\
\hline 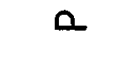 & & 3,0 & & 2,4 & 2,3 & 2,5 & 2,9 \\
\hline Média & 3,0 & 2,8 & 2,7 & 2,6 & 2,8 & 2,5 & 2,6 \\
\hline
\end{tabular}


Tabela 14. Teores de lignina total (\%) das progênies que compõem cada uma das procedências de E.globulus

\begin{tabular}{|c|c|c|c|c|c|c|c|}
\hline & \multicolumn{7}{|c|}{ PROCEDÊNCIAS } \\
\hline & 1 & 8 & 10 & 12 & 14 & 16 & 21 \\
\hline$n$ & 24,0 & 26,6 & 23,5 & 22,8 & 23,9 & 26,4 & 25,5 \\
\hline$\frac{0}{c}$ & 24,6 & 22,1 & 27,3 & 26,1 & 24,8 & 26,2 & 25,3 \\
\hline \& & 25,9 & 23,3 & 21,2 & 25,6 & 25,7 & 26,3 & 27,1 \\
\hline 1 & & 23,5 & 26,1 & 24,3 & 24,7 & 27,4 & 22,9 \\
\hline 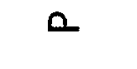 & & 23,5 & & 25,7 & 24,1 & 23,7 & 25,5 \\
\hline Média & 24,8 & 23,8 & 24,5 & 24,9 & 24,6 & 26,0 & 25,3 \\
\hline
\end{tabular}

Tabela 15. Teores de holocelulose (\%) das progênies que compõem cada uma das procedências de E.globulus

\begin{tabular}{|c|c|c|c|c|c|c|c|}
\hline & \multicolumn{7}{|c|}{ PROCEDÊNCIAS } \\
\hline & 1 & 8 & 10 & 12 & 14 & 16 & 21 \\
\hline n & 71,4 & 68,2 & 72,9 & 72,7 & 69,8 & 70,3 & 71,3 \\
\hline$\frac{ \pm}{c}$ & 69,9 & 73,8 & 68,6 & 69,2 & 69,6 & 69,9 & 70,5 \\
\hline 崩 & 70,5 & 71,6 & 76,2 & 69,7 & 71,0 & 68,4 & 69,0 \\
\hline 0 & & 71,7 & 69,0 & 70,1 & 71,0 & 66,6 & 73,2 \\
\hline 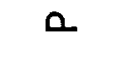 & & 71,8 & & 70,1 & 72,4 & 70,6 & 68,8 \\
\hline Média & 70,6 & 71,4 & 71,7 & 70,4 & 70,7 & 69,2 & 70,6 \\
\hline
\end{tabular}


Tabela 16. Teores de extrativos totais (\%) das progênies que compõem cada uma das procedências de E.globulus

\begin{tabular}{|c|c|c|c|c|c|c|c|}
\hline & \multicolumn{7}{|c|}{ PROCEDÊNCIAS } \\
\hline & 1 & 8 & 10 & 12 & 14 & 16 & 21 \\
\hline$n$ & 4,6 & 5,2 & 3,7 & 4,5 & 6,3 & 3,3 & 3,1 \\
\hline$\frac{1}{\pi}$ & 5,5 & 4,1 & 4,1 & 4,7 & 5,7 & 3,9 & 4,2 \\
\hline 我 & 3,6 & 5,1 & 2,6 & 4,7 & 3,3 & 6,3 & 3,9 \\
\hline 인 & & 4,8 & 4,9 & 5,5 & 4,3 & 5,9 & 4,0 \\
\hline$\circ$ & & 4,8 & & 4,2 & 3,6 & 5,7 & 5,6 \\
\hline Média & 4,6 & 4,8 & 3,8 & 4,7 & 4,6 & 4,8 & 4,2 \\
\hline
\end{tabular}

Tabela 17. Valores de rendimento depurado (\%) das progênies que compõem cada uma das procedências de E.globulus

\begin{tabular}{|c|c|c|c|c|c|c|c|}
\hline & \multicolumn{7}{|c|}{ PROCEDÊNCIAS } \\
\hline & 1 & 8 & 10 & 12 & 14 & 16 & 21 \\
\hline$n$ & 53 & 49 & 50 & 51 & 49 & 47 & 50 \\
\hline$\frac{d}{c}$ & 48 & 50 & 56 & 53 & 52 & 46 & 51 \\
\hline « & 52 & 51 & 48 & 52 & 46 & 50 & 48 \\
\hline 0 & & 50 & 50 & 50 & 51 & 48 & 49 \\
\hline$\circ$ & & 49 & & 49 & 50 & 48 & 48 \\
\hline Média & 51 & 50 & 51 & 51 & 50 & 48 & 49 \\
\hline
\end{tabular}


Tabela 18. Valores de número kappa das progênies que compõem cada uma das procedências de E.globulus

\begin{tabular}{|c|c|c|c|c|c|c|c|}
\hline & \multicolumn{7}{|c|}{ PROCEDÊNCIAS } \\
\hline & 1 & 8 & 10 & 12 & 14 & 16 & 21 \\
\hline$n$ & 20 & 19 & 19 & 17 & 22 & 18 & 15 \\
\hline$\frac{w}{c}$ & 19 & 18 & 19 & 22 & 24 & 20 & 16 \\
\hline$<$ & 22 & 18 & 18 & 22 & 19 & 22 & 21 \\
\hline 은 & & 18 & 18 & 17 & 18 & 22 & 17 \\
\hline 0 & & 19 & & 18 & 23 & 19 & 17 \\
\hline Média & 20 & 18 & 18 & 19 & 21 & 20 & 17 \\
\hline
\end{tabular}

Tabela 19. Teores de rejeito base madeira (\%) das progênies que compõem cada uma das procedências de E.globulus

\begin{tabular}{|c|c|c|c|c|c|c|c|}
\hline & \multicolumn{7}{|c|}{ PROCEDÊNCIAS } \\
\hline & 1 & 8 & 10 & 12 & 14 & 16 & 21 \\
\hline$n$ & 1,0 & 0,4 & 0,3 & 0,2 & 1,7 & 0,6 & 0,8 \\
\hline$\frac{0}{c}$ & 0,7 & 0,2 & 0,6 & 0,6 & 0,4 & 0,1 & 0,0 \\
\hline 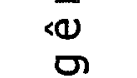 & 0,1 & 0,3 & 0,2 & 0,6 & 0,2 & 0,6 & 0,4 \\
\hline 은 & & 0,1 & 0,4 & 0,3 & 0,2 & 0,7 & 0,1 \\
\hline 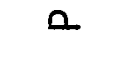 & & 0,8 & & 0,2 & 0,9 & 0,4 & 0,3 \\
\hline Média & 0,6 & 0,4 & 0,4 & 0,4 & 0,7 & 0,5 & 0,3 \\
\hline
\end{tabular}


Tabela 20. Valores da relação rendimento depurado/kappa das progênies que compõem cada uma das procedências de E.globulus

\begin{tabular}{|c|c|c|c|c|c|c|c|}
\hline & \multicolumn{7}{|c|}{ PROCEDÊNCIAS } \\
\hline & 1 & 8 & 10 & 12 & 14 & 16 & 21 \\
\hline n & 2,7 & 2,6 & 2,7 & 3,0 & 2,2 & 2,5 & 3,3 \\
\hline$\frac{0}{c}$ & 2,6 & 2,8 & 2,9 & 2,4 & 2,1 & 2,3 & 3,1 \\
\hline 迥 & 2,4 & 2,8 & 2,7 & 2,4 & 2,5 & 2,3 & 2,3 \\
\hline 0 & & 2,8 & 2,8 & 2,9 & 2,9 & 2,2 & 2,9 \\
\hline 0 & & 2,7 & & 2,8 & 2,2 & 2,5 & 2,8 \\
\hline Média & 2,6 & 2,7 & 2,8 & 2,7 & 2,4 & 2,4 & 2,9 \\
\hline
\end{tabular}

Tabela 21. Valores de peso específico aparente $\left(\mathrm{g} / \mathrm{cm}^{3}\right)$ das procedências de E.globlus em função de três níveis de refino (revoluções)

\begin{tabular}{cccccccc}
\hline & \multicolumn{7}{c}{ PROCEDÊNCIAS } \\
Revoluções & 1 & 8 & 10 & 12 & 14 & 16 & 21 \\
\hline 9000 & 0,563 & 0,533 & 0,593 & 0,535 & 0,527 & 0,511 & 0,497 \\
15000 & 0,572 & 0,557 & 0,595 & 0,624 & 0,615 & 0,570 & 0,604 \\
18000 & 0,631 & 0,578 & 0,648 & 0,636 & 0,565 & 0,587 & 0,573 \\
\hline
\end{tabular}

Tabela 22. Valores do grau Shopper-Riegler ( $\left.{ }^{\circ} \mathrm{SR}\right)$ das procedências de E.globulus em função de três níveis de refino (revoluções)

\begin{tabular}{cccccccc}
\hline & \multicolumn{8}{c}{ PROCEDÊNCIAS } \\
Revoluções & 1 & 8 & 10 & 12 & 14 & 16 & 21 \\
\hline 9000 & 26 & 16 & 24 & 26 & 24 & 23 & 20 \\
15000 & 34 & 28 & 46 & 42 & 33 & 28 & 34 \\
18000 & 58 & 28 & 49 & 53 & 40 & 38 & 34 \\
\hline
\end{tabular}


Tabela 23. Valores de volume específico aparente $\left(\mathrm{cm}^{3} / \mathrm{g}\right)$ das procedências de E.globulus em função de três níveis de refino (revoluções)

\begin{tabular}{cccccccc}
\hline & \multicolumn{7}{c}{ PROCEDÊNCIAS } \\
Revoluções & 1 & 8 & 10 & 12 & 14 & 16 & 21 \\
\hline 9000 & 1,78 & 1,88 & 1,69 & 1,87 & 1,90 & 1,96 & 2,01 \\
15000 & 1,75 & 1,80 & 1,68 & 1,60 & 1,63 & 1,75 & 1,66 \\
18000 & 1,58 & 1,73 & 1,54 & 1,57 & 1,77 & 1,70 & 1,75 \\
\hline
\end{tabular}

Tabela 24. Valores do índice de tração $(\mathrm{N} . \mathrm{m} / \mathrm{g})$ das procedências de E.globulus em função de três níveis de refino (revoluções)

\begin{tabular}{cccccccc}
\hline & \multicolumn{7}{c}{ PROCEDÊNCIAS } \\
Revoluções & 1 & 8 & 10 & 12 & 14 & 16 & 21 \\
\hline 9000 & 67,6 & 62,1 & 73,8 & 76,4 & 65,1 & 49,4 & 57,0 \\
15000 & 79,7 & 59,2 & 63,7 & 62,0 & 68,5 & 75,2 & 71,8 \\
18000 & 74,6 & 77,9 & 68,9 & 75,7 & 80,7 & 73,9 & 79,8 \\
\hline
\end{tabular}

Tabela 25. Valores do índice de rasgo $\left(\mathrm{mN} \cdot \mathrm{m}^{2} / \mathrm{g}\right)$ das procedências de E.globulus em função de três níveis de refino (revoluções)

\begin{tabular}{cccccccc}
\hline & \multicolumn{7}{c}{ PROCEDÊNCIAS } \\
Revoluções & 1 & 8 & 10 & 12 & 14 & 16 & 21 \\
\hline 9000 & 9,2 & 10,6 & 15,5 & 13,8 & 8,4 & 13,2 & 16,2 \\
15000 & 10,9 & 9,8 & 12,9 & 11,6 & 8,8 & 9,2 & 7,6 \\
18000 & 8,3 & 12,8 & 11,2 & 10,3 & 9,2 & 12,1 & 12,5 \\
\hline
\end{tabular}


Tabela 26. Valores do índice de arrebentamento $\left(\mathrm{kPa} \cdot \mathrm{m}^{2} / \mathrm{g}\right)$ das procedências de E.globulus em função de três níveis de refino (revoluções)

\begin{tabular}{cccccccc}
\hline & \multicolumn{8}{c}{ PROCEDÊNCIAS } \\
Revoluções & 1 & 8 & 10 & 12 & 14 & 16 & 21 \\
\hline 9000 & 5,4 & 5,4 & 5,1 & 5,3 & 5,2 & 5,9 & 5,5 \\
15000 & 4,7 & 4,3 & 5,1 & 5,6 & 5,3 & 5,1 & 4,9 \\
18000 & 4,9 & 5,2 & 5,7 & 5,2 & 5,7 & 5,9 & 5,9 \\
\hline
\end{tabular}

Tabela 27. Valores do índice de energia absorvida na tração $(\mathrm{J} / \mathrm{g})$ das procedências de E.globulus em função de três níveis de refino (revoluções)

\begin{tabular}{cccccccc}
\hline & \multicolumn{7}{c}{ PROCEDÊNCIAS } \\
Revoluções & 1 & 8 & 10 & 12 & 14 & 16 & 21 \\
\hline 9000 & 2,4 & 1,9 & 2,5 & 2,5 & 2,1 & 1,6 & 1,6 \\
15000 & 2,7 & 1,8 & 2,2 & 2,5 & 2,7 & 2,4 & 2,2 \\
18000 & 2,9 & 2,3 & 2,8 & 3,1 & 2,8 & 2,8 & 2,9 \\
\hline
\end{tabular}

Tabela 28. Valores do índice de rigidez na tração $(\mathrm{N} . \mathrm{m} / \mathrm{g})$ das procedências de E.globulus em função de três níveis de refino (revoluções)

\begin{tabular}{cccccccc}
\hline & \multicolumn{8}{c}{ PROCEDÊNCIAS } \\
Revoluções & 1 & 8 & 10 & 12 & 14 & 16 & 21 \\
\hline 9000 & 245 & 241 & 593 & 535 & 323 & 245 & 320 \\
15000 & 303 & 248 & 595 & 625 & 222 & 317 & 310 \\
18000 & 239 & 301 & 648 & 636 & 302 & 256 & 298 \\
\hline
\end{tabular}




\section{REFERÊNCIAS BIBLIOGRÁFICAS}

AMIDON,T.E. 1981. Effect of the wood properties of hardwoods on kraft paper properties.Tappi Journal, v.64, n.3, p.123-126, Mair.1981.

ASSOCIAÇÃO BRASILEIRA TËCNICA DE CELULOSE E PAPEL. Métodos de ensaio. São Paulo, 1974. 1v.

ASTALS, F. Estrutura e propriedades mecânicas e ópticas do papel. Apostila de Curso, Botucatu, 1995.

BALMELLI, G.; RESQUIN, F. Evaluación de orígenes de Eucalyptus globulus al séptimo año. Serie Técnica INIA, n.103. p.1-15, 1999.

BAMBER,R.K.The wood anatomy of eucalypts and papermaking. Appita, v.38, n.3, p.210-216, May1985.

BARRICHELO,L.E.G. Química da madeira. Piracicaba: ESALQ, 1976. 40p.

BARRICHELO, L.E.G.; BRITO, J.O. Potencialidade de Espécies Tropicais de Eucalipto para a Produção de Celulose Sulfato Branqueada. IPEF, n.13, p.9$38,1976$. 
BARRICHELO, L.E.G.; BRITO, J.O. El eucalipto como matéria prima para celulosa en Brasil. Separata de Investigación y Técnica del Papel, v.50 n.13, p.927-949, 1976.

BARRICHELO, L.E.G.; BRITO, J.O. Variações das características da madeira de Eucalyptus grandis e suas correlações com a produção de celulose. In: CONGRESSO BRASILERIO DE CELULOSE E PAPEL DE EUCALIPTO, 1., Trabalhos técnicos. São Paulo: $A B C P, 1977$. p.41-46.

BARRICHELO,L.E.G.; BRITO,J.O. A madeira das espécies de eucalipto como matéria-prima para a industria de celulose e papel. Série Divulgação PRODEPEF, n.13, p.1-145, 1976.

BARRICHELO, L.E.G.; BRITO, J.O. Celulose Sulfato de Madeiras de Diferentes Espécies de Eucalitpo, Silvicultura. v.8, n.28, p.734-737, 1983.

BARRICHELO,L.E.G.; BRITO,J.O.; COUTO,H.T.Z.; CAMPINHOS JR.,E. Densidade básica, teor de holecelulose e rendimento em celulose de madeira de Eucalyptus grandis. Silvicultura, v.8, n.32, p.802-808, set./out.1983.

BARRICHELO, L.E.G.; FOELKEL, C.E.B. Estudos para Produção de Celulose Sulfato de seis Espécies de Eucalypto, IPEF, n.12, p.77-95, 1976.

BEADLE, C.L.; TURNBULL, C.R.A.; DEAN, G.H. Environmental effects on growth and kraft pulp yeld of Eucalyptus globulus and E.nitens. Appita Journal, v.49, n.4, p.239-242, 1996./Resumo en TREECD on CD - ROM, 1973$99 / 10 /$ 
BORRALHO,N.M.G.; KANOWSKI,P.J.; COTTERILL,P.P. Genetic control of growth of Eucalyptus globulus in Portugal: 1 - genetic and phenotypic parameters. Silvae Genetica, v.41, n.1, p.39-45, 1992.

BOSIA, A.; et al. Paper - making characteristics of a further six Eucalypt species. Cellulosa e Carta, v.16, n.9, p.7-27, 1965. / Resumo en TREECD on CD ROM, 1939-72/

BRITO,J.O.; BARRICHELO,L.E.G.; MIGLIORINI,A.J.; SEIXAS,F.; MURAMOTO,M.C. Análise da produção energética e de carvão vegetal de nove espécies de eucalipto.Silvicultura, v.8, n.28, p.742-744, 1983.

BUGAJER,S. Pastas celulosicas sulfato branqueadas de folhosas - enfase especial ao eucalipto brasileiro. O Papel, v.40, n.8, p.47-53, ago.1979.

BUSTAMANTE, L. ; SANTOS, J.A. de los. Aptitud de diferentes epécies de eucalyptus como materia prima celulósica. In: CONGRESO LATINOAMERICANO DE CELULOSA Y PAPEL, 2., Torremolinos, INIA,1984. p.317-331.

CÁCERES, R.H. Producción y evaluación de pulpas celulósicas a partir de diferentes especies de Eucalyptus. In: CONGRESO LATINOAMERICANO DE CELULOSA Y PAPEL, 3., São Paulo, 1983. Trabalhos técnicos. São Paulo: ABCP, 1983. v.4, p.1043-1051. 
CHINCHOLE, P.R.; MEHTA, N.S. Anatomical and Chemical characteristics of Indian hardwoods with special reference to their suitability for pulp. Part II - (1) Eucalyptus globulus, (2) Erythrina suberosa, (3) Anogeissus latifolia. Indian Pulp Pap., v.22, n.9, p.507-514, 1968. / Resumo en TREECD on CD - ROM, 1939-72/

COTTERILL, P.; MACRAE, S. Improving eucalyptus pulp and paper quality using selection and good organization. Tappi Journal, v.80, n.6, p.82-89, 1997. /Resumo en TREECD on CD - ROM, 1973-99/10/

D’ALMEIDA,M.I.O. Composição Química dos Materias. In: Celulose e papel: tecnologia de fabricação da pasta celulósica. São Paulo: SENAI;IPT, 1982. p.43-98.

DEAN, G.H.,1985. Objectives for wood fibre quality and uniformity. In: POTTS,B.M.; BORRALHO,N.M.G.; REID,J.B.; CROMER,R.N.; TIBBITS,W.N.; RAYMOND,C.A., EUCALYPT PLANTATIONS: IMPROVING FIBRE YIELD AND QUALITY. Hobart, 1995. Proceedings. Sandy Bay: CRCTHF/IUFRO, 1995. v.1, p.5-9.

DIAS, J.F.L.S. Estudo das características tecnológicas das pastas produzidas industrialmente com madeiras de eucaliptos. Lisboa: Junta Investigações, 1972. 101p. 
DUTKOWSKI,G.; POTTS, B.; BORRALHO,N. Revised racial classification of Eucalyptus globulus ssp. globulus and the importance of including race in analysis of progeny trials. In: IUFRO CONFERENCE ON SILVICULTURE AND IMPROVEMENT OF EUCALIPTS, Salvador, 1997. Anais. Colombo: EMBRAPA,CNPF, 1997. v.1, p.322-329.

FAO. El eucalipto en la repoblación forestal, Roma, 1981. 747 p.

FERRARI,G.; MUGHINI,G. Variation of growth and wood quality traits in provenances of some Eucalyptus species in Italy. In: POTTS,B.M.; BORRALHO,N.M.G.; REID,J.B.; $\quad$ CROMER,R.N.; TIBBITS,W.N.; RAYMOND,C.A., EUCALYPT PLANTATIONS: IMPROVING FIBRE YIELD AND QUALITY. Hobart, 1995. Proceedings. Sandy Bay: CRCTHF/IUFRO, 1995. v.1, p.35-39.

FERREIRA, G.W., DA SILVA, M.C.M., GONZAGA, J.V., FOELKEL, C.E.B., DE ASSIS T. F.; RATNIEKS, E. Qualidade da Celulose Kraft-Antraquinona de Eucalyptus dunnii Plantado em Cinco Espaçamentos em relação ao eucalyptus grandis e Eucalyptus saligna, In: CONGRESSO ANUAL DE CELULOSE E PAPEL DA ABTCP, 30., São Paulo, 1997. Trabalhos apresentados. São Paulo: ABTCP, 1997. p. 293-307.

FERREIRA,P.J.; FIGUEIREDO,M.M. Efeito do cozimento e da refinação nas dimensões transversais de fibras de E. globulus. O Papel, v.62, n.1, p.7380 , jan. 2001

FOELKEL,C.E.B. Rendimentos em celulose sulfato de eucalyptus em função do grau de deslignificação e da densidade da madeira. IPEF, n.9, p.61-77, 1974a. 
FOELKEL, C.E.B. Produção em laboratório de celulose sulfato de madeira de Eucalyptus globulus, Piracicaba: ESALQ, 1974b. 14p.

FOELKEL,C.E.B. Madeira do eucalipto: da floresta ao digestor. Belo Oriente: CENIBRA, 1978. 25p.

FOELKEL,C.E.B.; BARRICHELO,L.E.G. Avaliação das madeiras para produção de celulose através de suas características estruturais: uma referência especial para o gênero Eucalyptus. In: SEMINÁRIO DE INTEGRAÇÃO FLORESTAINDÚSTRIA, Piracicaba, 1975: IPEF;ESALQ, p.5-33.

FOELKEL, C.E.B., BARRICHELO, L.E.G.; MILANEZ, A F. Estudo comparativo das madeiras de Eucalyptus saligna, E. paniculata, E. citrodora, E. maculata e E.tereticornis para produção de celulose sulfato. Piracicaba: ESALQ, 1975. 82p.

FOELKEL, C.E.B.; BRASIL, M.A.M.; BARRICHELO, L.E.G. Métodos de determinação da densidade básica de cavacos para coníferas e folhosas. IPEF, n.2/3, p.65-74, 1971.

FOELKEL, C.E.B.; MORA, E.; MENOCHELLI, S. Densidade básica: sua verdadeira utilidade como índice de qualidade da madeira de eucalipto para produção de celulose. O Papel, v.53, n.5, p.35-40, maio.1992.

FOELKEL, C.E.B., SIQUEIRA, L.R.O, ZVINAKEVICIUS, C., KATO, J.; ANDRADE, J.OM. Celulose Kraft de Eucalyptus "alba"de Santa Bárbara - MG, Cenibra Pesquisa, n.22, 10 p. 1977. 
FOELKEL,C.E.B.; ZVINAKEVICIUS,C.; ANDRADE,J.R.;KATO,J.; MEDEIROS,J. Eucaliptos tropicais na produção de celulose kraft. Cenibra Pesquisa, n.68, p.1-31, jul.1978.

FOELKEL,C.E.B. Kraft pulp yields of eucalypt wood in relation to degree of delignification and wood specific gravity.s.n.t. $6 \mathrm{p}$.

FONSECA,S.M.; OLIVEIRA,R.C.; SILVEIRA,P.N. Seleção da árvore industrial (Procedimentos, riscos, custos e benefícios). Revista Árvore, v.20, n.1, p.69-85, jan./mar.1996.

FOREST PRODTCTS LABORATORY. Summary of pulping and papermaking experiments on eucalyptus. USDA Forest Service FPL, n.2126, p.1-18, set.1958.

GAMOEDA, R,B., Pasta de alto rendimento de eucalipto. In: CONGRESSO ANUAL DE CELULOSE E PAPEL DA ABCP, 21., São Paulo,1988. Trabalhos apresentados. São Paulo: ABCP, 1988. p.265-287.

GOMIDE,J.L. Polpa de celulose: química dos processos alcalinos de polpação. Viçosa: UFV, 1979. 50p.

GONZAGA, J.V. Qualidade da madeira e da celulose kraft de treze espécies de Eucalyptus. Viçosa, 1983, 136p. Dissertação (Mestrado) - Universidade Federal de Viçosa. 
GONZAGA, J.V.; BUSNARDO, C.A.; DIAS, C.; FOELKEL, C.E.B. Estudo comparativo da qualidade da madeira de duas procedências de Eucalyptus camaldulensis e uma de Eualyptus globulus introduzidas na região de Guaiba - RS. In: CONGRESSO ANUAL DA ABCP, 17., São Paulo, 1984. Trabalhos apresentados. São Paulo: ABCP, 1984. v.1, p.325-345.

GONZAGA,J.V.; BUSNARDO,C.A.; FOELKEL,C.E.B.; MENOCHELLI,S. Celulose Kraft De Eucalyptus camaldulensis e Eucalyptus globulus. In: CONGRESSO ANUAL DA ABCP, 17., São Paulo, 1984. Trabalhos apresentados. São Paulo: ABCP, 1984. v.1, p.347-357.

GOYAL,G.C.; FISHER,J.J.; KROHN,M.J.; PACKOOD,R.E.; OLSON,J.R. Variability in pulping and fiber characteristics of hybrid poplar trees due to their genetic makeup, environmental factors, and tree age. Tappi Journal, v.82, n.5, p.141-147, May1999.

GREAVES,B.L.; BORRALHO,N.M.G. The influence of basic density and pulp yield on the cost of eucalypt kraft pulping: a theoretical model for tree breeding. Appita, v.49, n.2, p.90-95, 1996.

HATA, K.; SOGO, M.; BURHAN, E.D. Some experiments of pulping of Eucalyptus wood. Technical bulletin, Faculty of Agriculture, Kagawa University, v.23, n.1, p.92-96, 1971. /Resumo en TREECD on CD - ROM, 1973-99/10/

HILLIS,W.E. Wood extractives and their significance to the pulp and paper industries. New York: Academic Press, 1962. 513p. 
JACKSON,M.; FALK,B.; MOLDENIUS,S.; EDSTROM,A. A fabricação e o potencial da utilização de polpa de alto rendimento de eucalipto. O Papel, v.50, n.9, p.49-56, set.1989.

KIBBLEWHITE, R.P.; BAWDEN, A.D.; HUGHS, M.C. Harwood market kraft fibre and pulp qualities. Appita Journal, v.44, n.5, p.325-341, 1991. / Resumo en TREECD on CD - ROM, 1973-99/10/

KIBBLEWHITE,R.P.; JOHNSON,B.I.; SHELBOURNE,C.J.A. Kraft pulp qualities os Eucalyptus nitens, E.globulus, and E.maidenii, at ages 8 and 11 yearsta. New Zealand Journal of Forestry Science, v.30, n.3, p.447-457, 2000.

KOGA,M.I.T. Matérias-primas fibrosas. In: D'Almeida,M.L.O.Tecnologia de fabricação de pasta celulósica. São Paulo: SENAI;IPT, 1981, v.1 p.1442.

KRAMER, J.D. Pulping Eucalypts: a review. In: CONGRESSO ANUAL DE CELULOSE E PAPEL, São Paulo, 1998. São Paulo: ABCP, 1998. p.615-629.

LOW,C.B.; SHELBOURNE,C.J.A. Performance of Eucalyptus globulus, E. maidenii, E. nitens, and other eucalypts in northland and hawke $s$ bay at ages 7 and 11 years. New Zealand Journal of Forestry Science, v.29, n.2, p.274288, 1999.

LUDENA LARA,P.; BUENO ZARATE,J. Pulpa química al sulfato de tres espécies forestales de la selva central. Revista Forestal del Peru, v.16, n.2, p.49$56,1989$. 
MANFREDI, V. Variação do rendimento em celulose sulfato ao logo de tronco do Eucalyptus grandis Hill ex Maiden e E.saligna Smith. Piracicaba, 1985, 94p. Dissertação (Mestrado) - Escola Superior de Agricultura "Luiz de Queiroz", Universidade de São Paulo.

MAMERS, H.; BALODIS, V.; GARLAND, C.P.; LANGFORS, N.G.; MENZ, D.N.J.; CHIN, C.W.J. An assessment of de kraft pulping propertis of residual mature eucalypt rounwood from East Gippsland. Appita Journal, v.44, n.4, p.252-260, 1991. / Resumo en TREECD on CD - ROM, 1973-99/10/

MELO, R.; PAZ, J. Bleaching capacity of eucalipts grown in Chile. Investigación y técnica del papel, v.17, n.63, p.62-73, 1980. / Resumo en TREECD on CD - ROM, 1973-99/10/

MELLO H.A. do; BALLONI, E.A.; JACOB, W.S.; SIMOES, J.W.; KAGEYAMA,P.Y.; BARRICHELO, L.E.G.; BRITO, J.O. Variações das características da madeira de Eucalyptus grandis e suas correlações com a produção de celulose. In: CONGRESSO BRASILERIO DE CELULOSE E PAPEL DE EUCALIPTO, 1., São Paulo, 1977. Trabalhos técnicos. São Paulo: ABCP, 1977. p.53-73.

MEZZOMO,L.X.; MARTINS,M.A.; FOELKEL,C.E.B.; SACON,V. Potencialidade de quatro espécies de Eucalyptus cultivadas na Bahia, para produção de celulose solúvel branqueada. O Papel, v.58, n.11, p.71-80, nov.1997.

MIMMS, A.G.; KOCUREK,M.J.; PYATTE,J.A.; WRIGHT,E.E. Kraft pulping: a compilation of notes. Atlanta: TAPPI PRESS, 1993. p.179 
ONA,T.; WATANABE,Y; FUKAZAWA, k. Lignin variations in wood quality Characteristics of lignin in Eucalyptus camaldulensis and E.globulus. In IUFRO WORLD CONGRESS, 20., Tampere, 1995. Congress report, caring for the forest: research in a changing world. Jyvarskyla: Gummerus, 1995, v.2, 10p.

ORME,R.K. Eucalyptus Globulus Provenances. Forest Genetic Resources Information, n.7, p.19-33, 1978.

ORME,R.K. Progress with E. globulus provenance research. Silvicutura, v.8, n.31, p.483-6, jul./ago.1983.

PAL, D.; SAMUELSON, O. Oxygen - alkali cooking of wood meal. Part 9. Eucalyptus saligna and Eucalyptus globulus. Svensk-papperstidning. v.79, n.26, p. 531-536, 1976. / Resumo en TREECD on CD - ROM, 1973$99 / 10 /$

PALMER,E.R.; GANGULI,S.; DUTTA,A.P. Pulping trials of wood species growing in plantations in Kenya. Tropical Products Institute, n.L61, p.1-58, Sept.1982.

PALMER,E.R.; GIBBS,J.A.; GANGULI,S.; DUTTA,A.P. The pulping characteristics of Eucalyptus species grown in Malawi. Tropical Science, v.30, n.3, p.271$280,1990$. 
PAULA,J.E.; ALVES,J.L.H. Estrutura anatômica de madeiras indígenas para produção de energia e papel. Separata de Pesquisa Agropecuaria Brasileira, v.24, n.12, p.146, 1989.

PEREIRA,H.; ALMEIDA,M.H.; TOME,M.; PEREIRA,J.S. Eucalyptus globulus plantations: genetic, silvicultural and environmental control of fibre yield and quality. In: POTTS,B.M.; BORRALHO,N.M.G.; REID,J.B.; CROMER,R.N.; TIBBITS,W.N.; RAYMOND,C.A., EUCALYPT PLANTATIONS: IMPROVING FIBRE YIELD AND QUALITY, Hobart, 1995. Proceedings. Sandy Bay: CRCTHF/IUFRO, 1995. v.1, p.46-48.

PEREIRA,H.; SARDINHA,R. Chemical composition of Eucalyptus globulus Lab. Appita, v.37, n.8, p.661-664, Sept.1984.

QUEIROZ, M.G. Comportamiento de Várias Espécies de Eucalitpo en la Obtención de Pastas Sulfato, Investigación y Técnica del Papel, v.9, n.33, p,691-703, 1972.

REINOSO, E. Utilización de las pastas de Eucalipto en la fabricación del papel. In: CONGRESSO NAZIONALE DEI PERITI INDUSTRIALI CARTARI E CHEMICI CARTARI 13.,Roma, 1983. "Investigación y Técnica del Papel", n.75. 55.p - enero 1983

REPETTI,R. Relación entre las características de la madera y las propiedades del papel. In: SEMINARIO SOBRE CALIDAD DE LA MADERA EN LA PRODUCION FORESTAL, Buenos Aires, 1990. Anais. Buenos Aires: CIEF, 1990. p.11-30. 
SANSIGOLO,C.A.; CURVELO,A.A.S. Cinética da polpação em etanol-água e propriedades da polpa de Eucalyptus globulus. O Papel, v.56, n.8, p.39-45, ago.1995.

SANTOS,C.R. Métodos não-convencionais para determinação de celulose como parâmetro de seleção de árvores matrizes visando a produção de polpa kraft-AQ. Piracicaba, 2000. 117p. Dissertação (Mestrado) - Escola Superior de Agricultura "Luiz de Queiroz", Universidade de São Paulo.

SCARAMUZZI,G. First data on the volume proportions of wood tissues in some Italian grown Eucalyptus. In: CONFERÊNCIA MUNDIAL DO EUCALIPTO, 2., São Paulo, 1961. Relatório e documentos. São Paulo: FAO, 1961. v.2, p.1351-1357.

SEABRA, L.S.V. de; OLIVEIRA, J.F.S. A study on the pulping characteristics of wood of Eucalypts that can be grown in different ecologycal regions of Portugal. Publicações direção geral dos serviços florestais e aquicolas. v.39, p.148, 1972. / Resumo en TREECD on CD - ROM, 1973$99 / 10 /$

SCHIMLECK,L.R.; MICHELL,A.J.; RAYMOND,C.A.; MUNERI,A. Estimation of basic density of Eucalyptus globulus using near-infrared spectroscopy. Canadian Journal of Forest Research, v.29, n.2, p.194-201, Feb.1999.

SHIMOYAMA,V.R.S. Variações da densidade básica e características anatômicas e químicas da madeira em Eucalyptus. Piracicaba, 1990, 101p. Dissertação (Mestrado) - Escola Superior de "Agricultura Luiz de Queiroz", Universidade de Sao Paulo.. 
TAMOLANG,F.N.; WANGAARD,F.F. Relationships between hardwood fiber characteristics and pulp-sheet properties. Tappi, v.44, n.3, p.201-216, Mar.1961.

TECHNICAL ASSOCIATION OF THE PULP AND PAPER INDUSTRY.-CDROM.1998-1999 TAPPI Test Methods (compact disc). Atlanta:TAPPI 1999

TEJADA ARANA,M.; GONZALES MORA,E. Obtención de pulpa de Eucalyptus globulus mediante los procesos al sulfato y a la sosa con antraquinona. Revista Forestal del Peru, v.16, n.1, p.47-54, 1989.

TEXEIRA, M.L.; SOARES, A.R. Avaliação da qualidade da celulose de diferentes procedências de eucalyptus grandis hill ex. maiden. 0 papel, v.53, n.8, p.40-4, ago.1992.

TOMAZELLO FILHO,M. Estrutura anatômica da madeira de oito espécies de eucalipto cultivadas no Brasil. IPEF, n.29, p.25-36, 1985.

TOME,M.; RIBEIRO,F.; SOARES,P.; PEREIRA,H.; MIRANDA,I.; PINA,J.P. Effect of spacing on Eucalyptus globulus fibre yield and quality. In: POTTS,B.M.; BORRALHO,N.M.G.; REID,J.B.; $\quad$ CROMER,R.N.; TIBBITS,W.N.; RAYMOND,C.A., EUCALYPT PLANTATIONS: IMPROVING FIBRE YIELD AND QUALITY. Hobart, 1995. Proceedings. Sandy Bay: CRCTHF;IUFRO, 1995. v.1, p.60-63.

TURNER, C.H.; BALODIS, V.; DEAN, G.H. Variability in pulping quality of E.globulus from Tasmanian provenances. Appita, v.36, n.5, p.371-376, 1983. 
VAN WYK, W.J.; GERISCHER, G.F.R. Pulping Characteristics of Eucalyptus Provenance Trials Grown in the Western Cape Prt 1: Comparison between species, South African Forestry Journal, v.170, p.1-5, 1994.

VALENTE,C.A. O eucalipto e o seu melhoramento - EUC 2000. Estudos I \& D,. v.3, p.13-15, out.1993.

VALENTE, C.A.; FURTADO, F.P. O melhoramento do Eucalyptus globulus. - Uma abordagem ecológica. Estudos I \& D,. v.3, p.29-36, out.1993.

VALENTE, C.A.; MENDES de SOUZA, A.P.; FURTADO, F.P.; CARVALHO, A.P.de. O programa de melhoramento do Eucalyptus globulus na Portucel : a vertente tecnológica. Estudos I \& D,. v.3, p.37-45, out.1993

VASCONCELOS DIAS,R.L.; SILVA JÚNIOR, C.E. A influência da densidade básica da madeira de híbridos de Eucalyptus grandis em suas características químicas e propriedades de polpação e do papel. In: CONGRESO ANUAL DA ABTCP - Semana do Papel, 18., São Paulo, 1985. Anais. São Paulo:s.ed., 1985. p.31-55

VITAL,B.R.; JESUS,R.M.; VALENTE,O.F. Efeito da constituição química e da densidade da madeira de clones de Eucalyptus grandis na produção de carvão vegetal. Revista Arvore, v.10, n.2, p.151-60, jul./dez. 1986.

WALLIS, A.F.A; WEARNE, R.H., WRIGHT, P.J. Analytical characteristics of plantation eucalypt woods relating to kraft pulp yields. Appita Journal, v.49, n.6, p.427-432, 1996. / Resumo en TREECD on CD - ROM, 1973$99 / 10 /$ 
WANGAARD,F.F. Fiber characteristics in relation to paper properties. In: IUFRO MEETING DIVISION, 5., Pretoria, 1973. Proceedings. Pretoria, 1973. v.5, p.2262-2301.

WATSON,A.J. Influence of chemical constituents on the papermaking properties of pulps from eucalyptus regnans F.Muell. Appita, v.14, n.4, p.144-158, Jan.1961.

WATSON,A.J.; DADSWELL,H.E. Influence of fibre morphology on paper properties. part 1 - Fibre length. Appita, v.14, n.5, p.168-178, Mar.1961.

WEHR,T.R. Variações nas características da madeira de Eucalyptus grandis e suas influencias na qualidade de cavacos em cozimentos kraft. Piracicaba, 1991. 98p. Dissertação (Mestrado) - Escola Superior de Agricultura "Luiz de Queiroz", Universidade de Sao Paulo.

WILLIAMS,M.D.; BEADLE,C.L.; TURNBULL,C.R.A.; DEAN,G.H.; FRENCH,J. Papermaking potential of plantation eucalypts. In: POTTS,B.M.; BORRALHO,N.M.G.; REID,J.B.; CROMER,R.N.; TIBBITS, W.N.; RAYMOND, C.A., EUCALYPT PLANTATIONS: IMPROVING FIBRE YIELD AND QUALITY. Hobart, 1995. Proceedings. Sandy Bay: CRCTHF;IUFRO, 1995. v.1, p.7378.

ZARATE,J.B.; GIRONDA,C.T. Pulpa quimica al sulfato de Eucalyptus globulus Labill. en Cuzco, Cajamarca y Junin. Revista Forestal del Peru, v.10, n.1/2, p.139-157, 1980/1981 